Article

\title{
Self-Tuning Fuzzy Control for Seismic Protection of Smart Base-Isolated Buildings Subjected to Pulse-Type Near-Fault Earthquakes
}

\author{
Dahai Zhao ${ }^{1, *}$, Yang Liu ${ }^{1}$ and Hongnan $\mathrm{Li}^{2}$ \\ 1 School of Civil Engineering and Mechanics, Yanshan University, Qinhuangdao 066004, China; \\ zdhly0227@126.com \\ 2 School of Civil Engineering, Dalian University of Technology, Dalian 116024, China; hnli@dlut.edu.cn \\ * Correspondence: zhaodahai@126.com; Tel.: +86-335-806-7926
}

Academic Editor: Steve C.S. Cai

Received: 10 December 2016; Accepted: 9 February 2017; Published: 16 February 2017

\begin{abstract}
Pulse-type near-fault earthquakes have obvious long-duration pulses, so they can cause large deformation in a base-isolated system in contrast to non-pulse-type near-fault and far-field earthquakes. This paper proposes a novel self-tuning fuzzy logic control strategy for seismic protection of a base-isolated system, which can operate the control force of the piezoelectric friction damper against different types of earthquakes. This control strategy employs a hierarchic control algorithm, in which a higher-level supervisory fuzzy controller is implemented to adjust the input normalization factors and output scaling factor, while a sub-level fuzzy controller effectively determines the command voltage of the piezoelectric friction damper according to current level of earthquakes. The efficiency of the proposed control strategy is also compared with uncontrolled and maximum passive cases. Numerical results reveal that the novel fuzzy logic control strategy can effectively reduce the isolation system deformations without the loss of potential advantages of base-isolated system.
\end{abstract}

Keywords: pulse-type near-fault earthquake; base-isolation; fuzzy logic control (FLC); piezoelectric friction damper; vibration control

\section{Introduction}

Over the past decades, base isolation has been demonstrated to be an effective means to protect crucial structures and their contents from the destructive effects of dynamic excitations. The performance of base-isolated structures against near-fault earthquakes characterized by long-duration pulses with peak velocities has been investigated by several researchers [1,2]. Recent research results have shown that near-fault earthquakes characterized by long-duration pulses with peak velocities will result in significant base displacements and inter-story drifts of a seismically isolated structure [3]. Kalkan and Kunnath [4] showed that the fling-step effect would mainly excite the first order modal response of the structures with middle and long natural vibration period, and cause the maximum deformation of the structure at the bottom, which would result in the failure mode of the structure. Providakis [5] pointed out that isolation bearings will have a large deformation when the base-isolated structures with long natural vibration period are subjected to pulse-type near-fault earthquakes. Yang [6] examined the performance of a base-isolated structure under the action of near-fault earthquakes with fling-step effect. He found that the base displacement of the base-isolated structure exceeded the permissible displacement of the isolation bearings. The base-isolated structure may cause lateral instability, and the fling-step effect is more harmful than the rupture forward directivity for the base-isolated structure. 
Due to the large isolator displacements, the isolated structure will suffer some serious problems, such as large permanent base displacement, failure of the isolation bearing and overturning of the superstructure [7]. In addition, as a result of large isolator displacements, the size of the isolation device will significantly increase, which may require much larger seismic gaps between buildings or much larger bridge expansion joints. Therefore, these requirements increase the cost of the construction, which contradicts the primary goal of seismic isolation, which is to design structures more efficiently and economically [8]. In order to enhance the performance of the base-isolated structures subjected to pulse-type near-fault excitations, many kinds of control devices have been proposed [9-11]. Passive supplemental damping devices can reduce the deformations of the isolation bearings during strong ground motions. However, they may also induce large damper forces and result in increased floor accelerations [12]. Furthermore, when the structure is subjected to weak or moderate earthquakes, passive devices may adversely affect the isolation system since the desired isolation characteristics may be different for these earthquakes.

Semi-active control is an effective control alternative that regulates the output power of dampers according to current structural responses. Therefore, semi-active control has better adaptability than traditional passive control. Furthermore, semi-active control requires less power compared to active control, which uses powerful actuators to achieve ideal effects. For these reasons, semi-active control devices have been receiving considerable attentions in recent years. Nagarajaiah and Sahasrabudhe [13] proposed a variable stiffness device that is used in a sliding isolation system to reduce the seismic response of a base-isolated structure, and the effectiveness of the semi-active device was proved by numerical analytical and experimental studies. Shook et al. [14] proposed a super elastic semi-active damping device in a base-isolated structure and its damping performance was thoroughly analyzed and evaluated. Madhekar and Jangid [15] analyzed and evaluated the dynamic response of a seismically isolated benchmark bridge equipped with viscous and variable dampers, and assessed the performance of these dampers.

The goal of utilizing a semi-active device in a base-isolated structure is to mitigate the displacement response of the isolation system according to the current stage of excitation without an obvious increase in the superstructure response. In order to utilize the full capabilities of the semi-active devices employed in a semi-active isolation system, an effective control algorithm is essential. Due to the uncertainties in the nature of earthquakes and the characteristics of base-isolated systems, the task of developing an optimal controller is a challenging task. For instance, a controller designed for near-fault earthquakes that cause significant deformations in the isolation system might develop large damper forces during a far field earthquake of generally moderate excitation. As a result, the isolation system may not perform as expected, and a significant increase in the acceleration response of the superstructure may be observed. Alternatively, if the controller is designed for an earthquake with far-field characteristics, the damper force may not be large enough to effectively reduce the structural responses during the pulse-type ground motion. Thus, semi-active dampers need an adaptive control strategy for both far-field and near-field earthquakes.

Recently, fuzzy logic control has been shown to be a promising control algorithm and has been widely used by many researchers for the control of semi-active devices due to its superiority and effectiveness in dealing with complex, uncertain, and nonlinear systems [16]. Das et al. [17] studied the fuzzy control for seismic protection of civil structures using MR dampers. Kim and Roschke [18] adopted the supervisory fuzzy control technique in a similar manner to MR dampers in order to reduce seismic response of a base-isolated benchmark building. Ozbulut and Stefan [19] developed a supervisory fuzzy logic controller and a GA-based self-organizing fuzzy logic controller for piezoelectric friction dampers that are employed as semi-active devices in the base-isolated structure. An adaptive fuzzy neural control strategy was also developed by Ozbulut et al. [20] to adjust the contact force of the variable friction dampers (VFDs) that are used in a smart isolation system. In addition, Zhao and Li [21] proposed a new fuzzy logic controller that is designed for seismic protection of base-isolated structures utilizing piezoelectric friction damper against near-fault earthquakes for different ground sites. 
In this study, an improved self-tuning fuzzy logic control strategy is proposed in order to adjust the contact force of the piezoelectric friction damper (PFD) that is used in a smart isolation system. The control strategy employs an intelligent upper-level supervisory controller and a sub-level knowledge-based fuzzy controller. In this control strategy, the supervisory controller provides a mechanism to identify the nature of the earthquake, while the sub-level fuzzy controller specifies the command voltage for the damper by using isolation displacement and velocity as the two input variables. In particular, the supervisory controller tunes normalization factors of the sub-level controller inputs and the scaling factor of the sub-level controller outputs in order to improve the performance of the controller under different types of earthquakes. Taking into account that the pulse-type near-fault earthquake contains great acceleration and velocity pulses, seismic acceleration and seismic velocity are selected as two inputs of the supervisory controller. In order to verify the adaptability of the proposed control strategy under earthquakes with different intensities, and pulse-type near-fault earthquakes, non-pulse-type near-fault earthquakes and far-field earthquakes are employed as external excitations in the numerical simulations. For comparison purposes, maximum passive operation of the PFD and uncontrolled case are also considered in the simulations. A series of numerical simulations for the base-isolated building is performed to assess the performance of the control strategy.

\section{Pulse-Type near Fault Ground Motion}

In recent decades, many destructive strong earthquakes occurred throughout the world. Some researchers have obtained a large amount of data records for near-fault strong earthquakes. These earthquakes produced very serious damage to engineering structures, which aroused the attention to the seismological community and the engineering field [22].

A large number of previous studies indicated that some near-fault earthquakes have unique characteristics compared with far-field earthquakes, such as permanent ground displacement, significant rupture forward directivity and fling-step effect. Among these characteristics, pulse effects, such as rupture forward directivity and fling-step effect, can cause remarkable velocity pulses. Thus, compared with non-pulse-type near-fault earthquakes and far-field earthquakes, there exist significant differences in the amplitude, frequency and duration in pulse-type near-fault earthquakes, which aggravates the damage to the engineering structure. In general, for pulse-type near-fault earthquakes, the amplitudes of displacement, velocity and acceleration are all large. The low frequency component is abundant and the characteristic period is prolonged. Therefore, the near-fault earthquakes have high energy in the initial stage, which will result in large structural damage [23].

Previous research results indicate that, for pulse-type near-fault earthquakes, the ratio of peak ground velocity (PGV) to peak ground acceleration (PGA) is large. Some scholars have pointed out that PGV/PGA is mainly utilized to identify the pulse-effect of near-fault earthquakes. When PGV/PGA is more than 0.2 , the pulse-effect is very obvious. Therefore, PGV/PGA of pulse-type near-fault earthquakes is more than 0.2 in this paper, and the fault distances are less than $20 \mathrm{~km}$. In addition, for the selection of pulse-type near-fault earthquakes, the following criteria are used to distinguish the velocity pulse: the velocity time history curve of pulse-type near-fault earthquake contains a sharp bulge, and the duration for velocity pulse is above $0.5 \mathrm{~s}$. In order to compare the control effectiveness and adaptability of the proposed control strategy under different types of earthquakes, non-pulse-type near-fault earthquakes and far-field earthquakes are selected. Table 1 shows the selected seismic records and the characteristics of the data. The data source is from the Pacific Earthquake Engineering Research (PEER) Center strong earthquake database: http:// peer.berkeley.edu. In this table, code A represents near-fault earthquakes with fling-step effect, code B represents near-fault earthquakes with rupture forward directivity, code $\mathrm{C}$ represents non-pulse-type near-fault earthquakes, and code $\mathrm{D}$ represents far-field earthquakes. 
Table 1. Earthquake records and their characteristic parameters.

\begin{tabular}{|c|c|c|c|c|c|c|c|c|}
\hline Type & Code & Earthquake & $\begin{array}{l}\text { Station and } \\
\text { Direction }\end{array}$ & $\begin{array}{l}\text { Magnitude } \\
\left(\mathrm{M}_{\mathrm{w}}\right)\end{array}$ & $\begin{array}{c}\text { PGA } \\
\text { (g) }\end{array}$ & $\begin{array}{l}\text { PGV } \\
(\mathrm{cm} / \mathrm{s})\end{array}$ & $\begin{array}{l}\text { PGVI } \\
\text { PGA }\end{array}$ & $\begin{array}{c}\text { Fault } \\
\text { Distance }(\mathbf{k m})\end{array}$ \\
\hline \multirow{4}{*}{$\begin{array}{l}\text { Fling-step effect } \\
\text { near-fault } \\
\text { earthquakes }\end{array}$} & A1 & Chi-Chi & TCU052-NS & 7.6 & 0.411 & 95.7 & 0.233 & 0.06 \\
\hline & A2 & Chi-Chi & TCU052-EW & 7.6 & 0.341 & 159.0 & 0.466 & 0.06 \\
\hline & A3 & Chi-Chi & TCU068-NS & 7.6 & 0.452 & 263.0 & 0.581 & 0.50 \\
\hline & $\mathrm{A} 4$ & Chi-Chi & TCU068-EW & 7.6 & 0.555 & 176.5 & 0.318 & 0.50 \\
\hline \multirow{4}{*}{$\begin{array}{l}\text { Rupture forward } \\
\text { directivity } \\
\text { near-fault } \\
\text { earthquakes }\end{array}$} & B1 & Northridge & WPI-316 & 7.1 & 0.319 & 67.4 & 0.211 & 7.10 \\
\hline & B2 & Northridge & WPI-046 & 7.1 & 0.446 & 92.7 & 0.208 & 7.10 \\
\hline & B3 & Chi-Chi & TCU102-EW & 7.6 & 0.308 & 87.2 & 0.290 & 1.19 \\
\hline & B4 & Chi-Chi & TCU120-EW & 7.6 & 0.233 & 62.6 & 0.280 & 9.87 \\
\hline \multirow{4}{*}{$\begin{array}{l}\text { Non-pulse-type } \\
\text { near-fault } \\
\text { earthquakes }\end{array}$} & $\mathrm{C} 1$ & Chi-Chi & TCU071-EW & 7.6 & 0.530 & 69.83 & 0.080 & 4.88 \\
\hline & $\mathrm{C} 2$ & Chi-Chi & TCU072-EW & 7.6 & 0.480 & 85.51 & 0.180 & 7.87 \\
\hline & $\mathrm{C} 3$ & Chi-Chi & TCU078-EW & 7.6 & 0.442 & 42.14 & 0.100 & 8.27 \\
\hline & $\mathrm{C} 4$ & Chi-Chi & TCU079-EW & 7.6 & 0.590 & 64.49 & 0.110 & 10.95 \\
\hline \multirow{4}{*}{$\begin{array}{l}\text { Far-field } \\
\text { earthquakes }\end{array}$} & D1 & Taft & No.095-S69E & 7.7 & 0.172 & 17.2 & 0.099 & 43.0 \\
\hline & D2 & Taft & No.095-N21E & 7.7 & 0.153 & 17.8 & 0.116 & 43.0 \\
\hline & D3 & EI Centro & No.117-S90W & 7.1 & 0.214 & 36.9 & 0.172 & 40.0 \\
\hline & D4 & EI Centro & No.117-S00E & 7.1 & 0.349 & 33.5 & 0.096 & 40.0 \\
\hline
\end{tabular}

The acceleration and velocity time history curves of the selected four types of earthquakes are shown in Figure 1. It can be seen that the energy of pulse-type near-fault earthquakes accumulates rapidly. This will result in an impact-type ground motion with immense amplitude, obvious pulse waveform and short seismic duration. In addition, from the time history curves, it can be shown that velocity pulse induced by fling-step effect has the characteristic of a single pulse, and the velocity pulse induced by rupture forward directivity has the characteristic of bidirectional velocity pulses. In addition, the velocity time history curve with rupture forward directivity possesses multiple-pulse characteristics. The average elastic acceleration and velocity response spectra for the selected earthquakes with 5\% damped ratio are shown in Figure 2. It can be seen from the figure that, with respect to non-pulse-type near-fault earthquake and far-field earthquake, the spectra of acceleration and velocity for pulse-type near-fault earthquake in long period section significantly increase. For a base-isolated structure, the basic period is generally large. Therefore, it is very sensitive to pulse-type near-fault earthquakes.
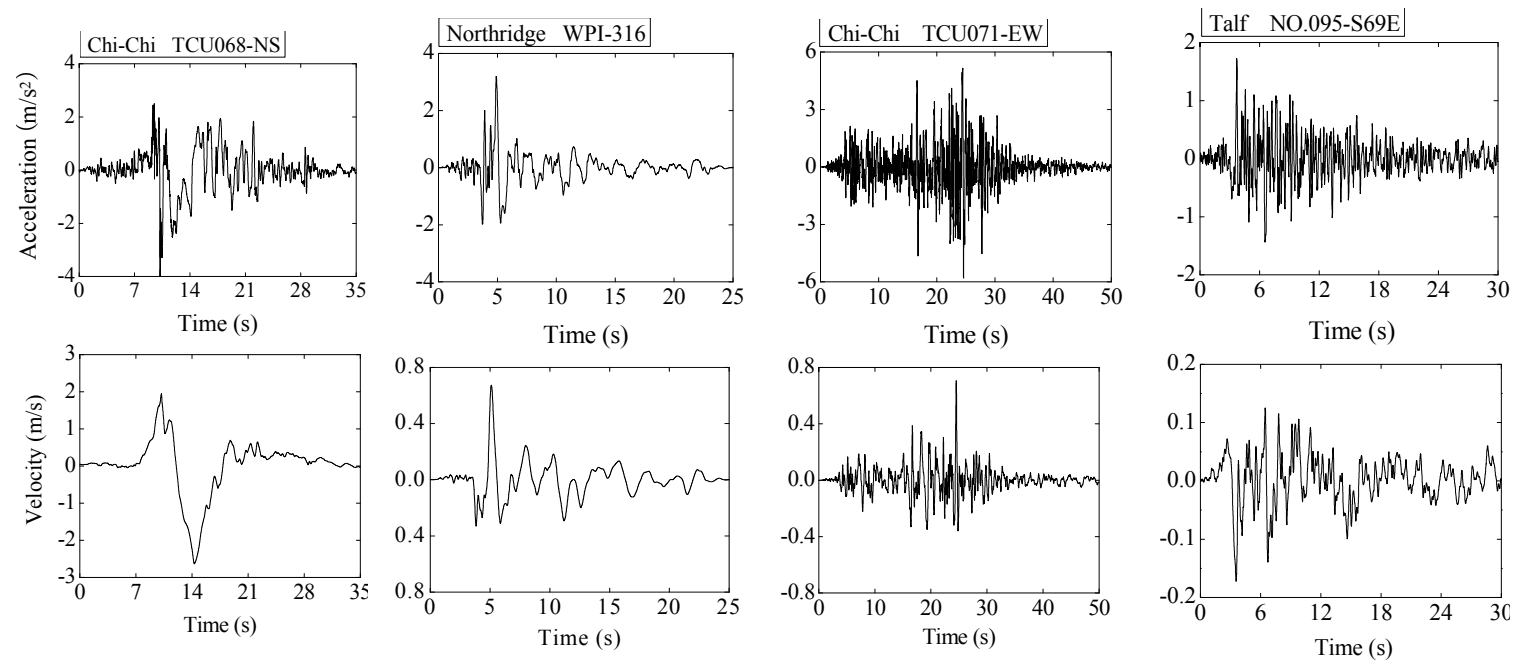

(a)

(b)

(c)

(d)

Figure 1. Acceleration and velocity time history curves for different types of earthquakes: (a) fling-step effect; (b) rupture forward directivity; (c) non-pulse-type; and (d) far-field. 


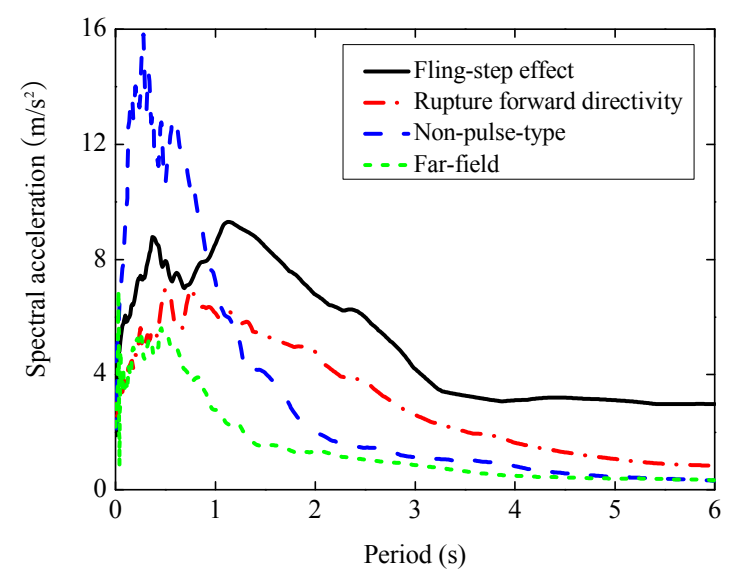

(a)

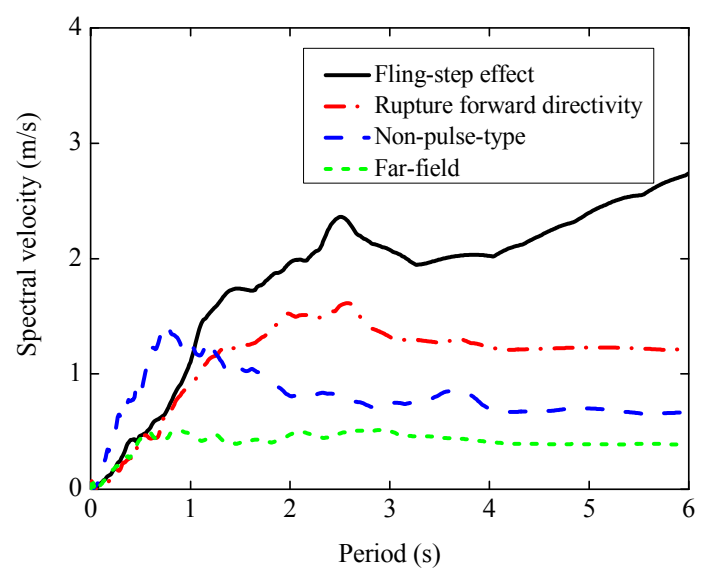

(b)

Figure 2. Average acceleration and velocity response spectra for different types of earthquakes: (a) spectra acceleration; and (b) spectra velocity.

\section{Modeling of Base-Isolated Structure with Piezoelectric Friction Dampers}

In this section, a five-story base-isolated structure is selected to investigate the performance of the following proposed control strategy. This base-isolated structure is equivalent to a lumped-mass model with one degree of freedom per floor. It is assumed that the superstructure of the base-isolated building remains elastic during the seismic excitation, as is usually the case for a base-isolated building. The schematic diagram of the semi-active base-isolated structure with PFD is shown in Figure 3.

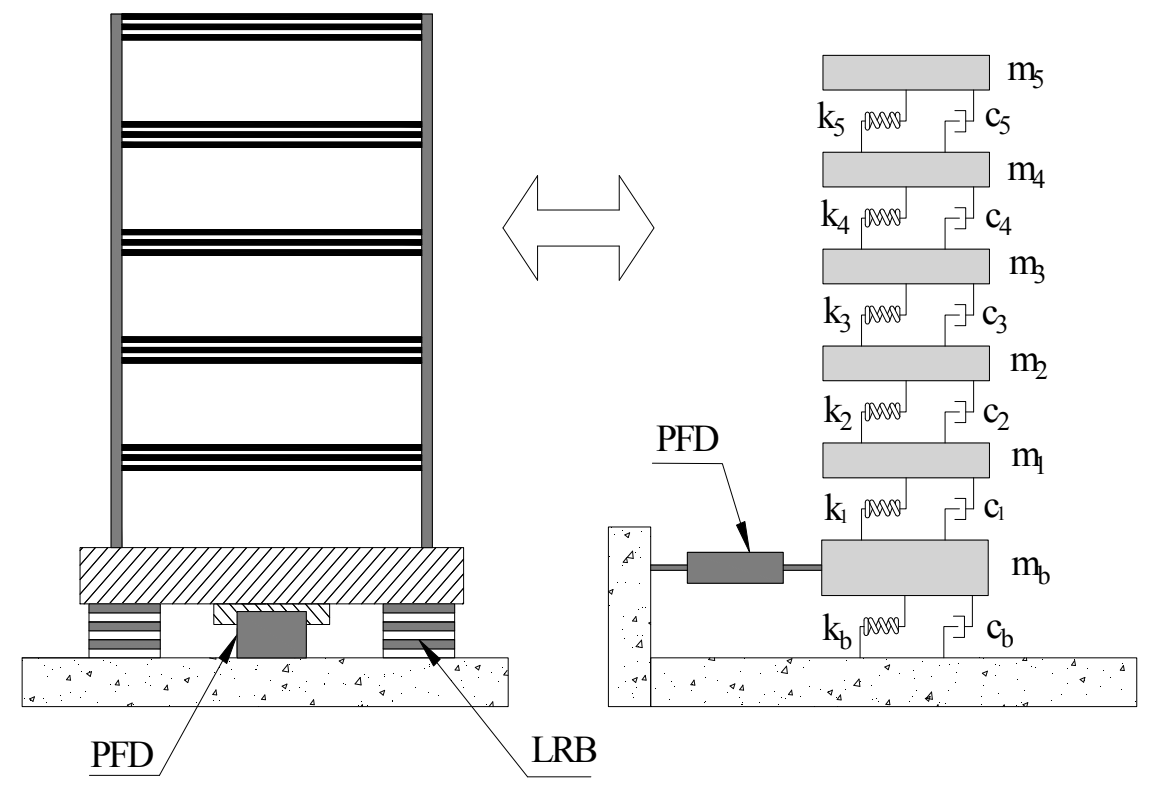

Figure 3. Model of the base-isolated structure.

The fundamental period of the five-story base-fixed structure equals $0.3 \mathrm{~s}$, with a damping of $2 \%$ in the first mode. The isolation system is composed of lead rubber bearing (LRB) and assumed to have nonlinear force-deformation behavior with viscous damping. The relevant parameters of the superstructure and the isolation system are listed in Table 2. To improve the performance of the base-isolated structure under different types of earthquakes, PFD is installed on the base of the base-isolated structure. 
Table 2. Parameters for the base-isolated structure.

\begin{tabular}{cccc}
\hline Floor & Mass & Stiffness $(\mathbf{K N} / \mathbf{m})$ & Damping Coefficient $(\mathrm{KN} \cdot \mathbf{s} / \mathbf{m})$ \\
\hline Base floor & $6800 \mathrm{~kg}$ & 2315 & 7.45 \\
1 & $5897 \mathrm{~kg}$ & 33,732 & 67 \\
2 & $5897 \mathrm{~kg}$ & 29,093 & 58 \\
3 & $5897 \mathrm{~kg}$ & 28,621 & 57 \\
4 & $5897 \mathrm{~kg}$ & 24,954 & 50 \\
5 & $5897 \mathrm{~kg}$ & 19,059 & 38 \\
\hline
\end{tabular}

\subsection{Equation of Motion for a Base-Isolated Structure}

Consider an $n$-degree of freedom base-isolated structure with piezoelectric friction dampers at the isolation floor subject to seismic acceleration $\ddot{x}_{g}$. The equation governing the dynamic response of the structural system is given by

$$
\mathbf{M} \ddot{\mathbf{x}}(t)+\mathbf{C} \dot{\mathbf{x}}(t)+\mathbf{K} \mathbf{x}(t)=-\mathbf{M I} \ddot{x}_{g}(t)+\mathbf{D} F(t)
$$

where $\mathbf{M}, \mathbf{C}, \mathbf{K}$ represent the $n \times n$ mass, damping, and stiffness matrices, respectively; $\mathbf{x}(t), \dot{\mathbf{x}}(t)$, and $\ddot{\mathbf{x}}(t)$ are $n \times 1$ displacement, velocity, and acceleration vectors, respectively; $\mathbf{I}$ is an $n$-dimensional identity matrix; $\mathbf{D}$ is an $n \times 1$ damper location vector; and $F(t)$ is the damping force of damper and LRB.

Rewriting Equation (1) in state-space form:

$$
\dot{\mathbf{z}}(t)=\mathbf{A z}(t)+\mathbf{B} F(t)+\mathbf{H} \ddot{x}_{g}(t)
$$

where

$$
\mathbf{z}(t)=\left[\begin{array}{c}
\mathbf{x}(t) \\
\dot{\mathbf{x}}(t)
\end{array}\right], \mathbf{A}=\left[\begin{array}{cc}
\mathbf{0} & \mathbf{I} \\
-\mathbf{M}^{-1} \mathbf{K} & \mathbf{M}^{-1} \mathbf{C}
\end{array}\right], \mathbf{B}=\left[\begin{array}{c}
\mathbf{0} \\
-\mathbf{M}^{-1} \mathbf{D}
\end{array}\right], \mathbf{H}=\left[\begin{array}{c}
\mathbf{0} \\
-\mathbf{I}
\end{array}\right]
$$

\subsection{Model of Piezoelectric Friction Damper}

As a novel semi-active control device, piezoelectric friction dampers have been widely investigated by many researchers $[24,25]$. Recently, the authors also proposed a piezoelectric friction damper and investigated in their performances theoretically and experimentally [26]. Piezoelectric friction dampers utilize piezoelectric stacks to regulate the damping force and provide a satisfied friction force. The controllable friction force is favorable to ensure energy dissipation for various levels of earthquakes.

The contact force of the damper is expressed as

$$
N(t)=N_{p r e}+C_{p z} V(t)
$$

where $N(t)$ denotes the total contact force, $N_{\text {pre }}$ denotes the constant preload of the piezoelectric friction damper, $C_{p z}$ denotes the piezoelectric coefficient of the piezoelectric actuator, and $V(t)$ denotes the input voltage of piezoelectric stack actuator.

During the movement of the base-isolated structure, a friction damper has two possible motion states: sticking and slipping phases. The friction force of the piezoelectric friction damper is expressed as

$$
\begin{gathered}
f(t)=-\mu N(t) \operatorname{sgn}(\dot{x}), \dot{x} \neq 0 \\
-\mu N(t) \leq f(t) \leq \mu N(t), \dot{x}=0
\end{gathered}
$$

where $\mu$ denotes the friction coefficient of the damper, $\operatorname{sgn}()$ denotes the sign function related to the slip rate of the damper, and $f(t)$ denotes the damping force of the piezoelectric friction damper. 
In the sticking phase, the absolute value of the friction force, $f_{s}$, can be approximately expressed as follows:

$$
\begin{gathered}
f_{s}=-\mu N(t) \operatorname{sgn}(\dot{x}) \text { when } f_{s}=\left|f_{i}+f_{r}\right|,|f(t)| \geq f_{s} \\
f_{i}=m_{t} \ddot{x}_{g}=\left(m_{b}+\sum_{i=1}^{n} m_{i}\right) \ddot{x}_{g}, f_{r}=k_{b} x_{b}
\end{gathered}
$$

where $f_{i}$ is the inertial force applied to the mass; $f_{r}$ is the restoring force provided by the isolation bearing; $m_{i}$ is the mass of the superstructure; $m_{b}$ and $k_{b}$ are the mass and stiffness of the base isolator, respectively; and $x_{b}$ is the displacement of the base isolator. The parameters $N_{p r e}, C_{p z}, \mu$ and $V_{\max }$ of the piezoelectric friction damper are set to $2500 \mathrm{~N}, 2.5 \mathrm{~N} / \mathrm{V}, 0.4$ and $1000 \mathrm{~V}$, respectively.

\subsection{Modeling of Lead Rubber Bearing}

In a lead rubber bearing, a central lead-core is used to provide an additional means of energy dissipation and initial rigidity against minor earthquakes and winds. The LRBs also provide an additional hysteretic damping through the yielding of the lead-core. The force-deformation behavior of the LRB is generally represented by non-linear characteristics. For the present study, Wen's model is used to characterize the hysteretic behavior of the LRBs. The restoring force developed in the isolation bearing is given by

$$
f_{b}(t)=\alpha k_{b} x_{b}+(1-\alpha) F_{y} Z
$$

where $\alpha$ is an index which represents the ratio of post- to pre-yielding stiffness; $k_{b}$ is the initial stiffness of the bearing; $x_{b}$ is the displacement of the isolation layer; $F_{y}$ is the yield strength of the bearing; and $\mathrm{Z}$ is the non-dimensional hysteretic displacement component satisfying the following non-linear first order differential equation:

$$
q \dot{Z}=A \dot{x}_{b}-\beta\left|\dot{x}_{b}\right| Z|Z|^{n-1}-\tau \dot{x}_{b}|Z|^{n}
$$

where $q$ is the yield displacement; and dimensionless parameters $A, \beta, \tau$ and $n$ are selected to determine the shape of the nonlinear hysteresis loops. The parameter $n$ is an integer constant, which controls the smoothness of transition from elastic to plastic response. The values of $q=0.025 \mathrm{~m}, A=1, \beta=0.5$, $\tau=0.5$ and $n=2$ have been selected in this study to characterize the hysteretic behavior of the LRB.

\section{Self-Tuning Fuzzy Control Strategy}

In this section, self-tuning control strategy is designed to adjust the contact force of PFDs by controlling the real-time voltage of PFD according to the level and type of current external excitation.

\subsection{Process Architecture of Self-Tuning Control Strategy}

The self-tuning control strategy adopts a hierarchic structure that consists of a supervisory controller and a sub-level controller. Taking into account that the pulse-type near-fault earthquake has large acceleration amplitudes and velocity pulses, the supervisory controller is employed to evaluate the nature of the earthquake according to the current acceleration and velocity level. A sub-level controller is designed to determine the command voltage of the PFD. Base displacement and velocity are employed as two input variables, and the command voltage is defined as a single output for the sub-level controller. Since the amplitudes of base displacement and velocity differ greatly from near-fault and far-field earthquakes, the decision on the normalization factor and the scaling factor is evaluated by the supervisory controller. The block diagram of the proposed self-tuning fuzzy control strategy is shown in Figure 4. 


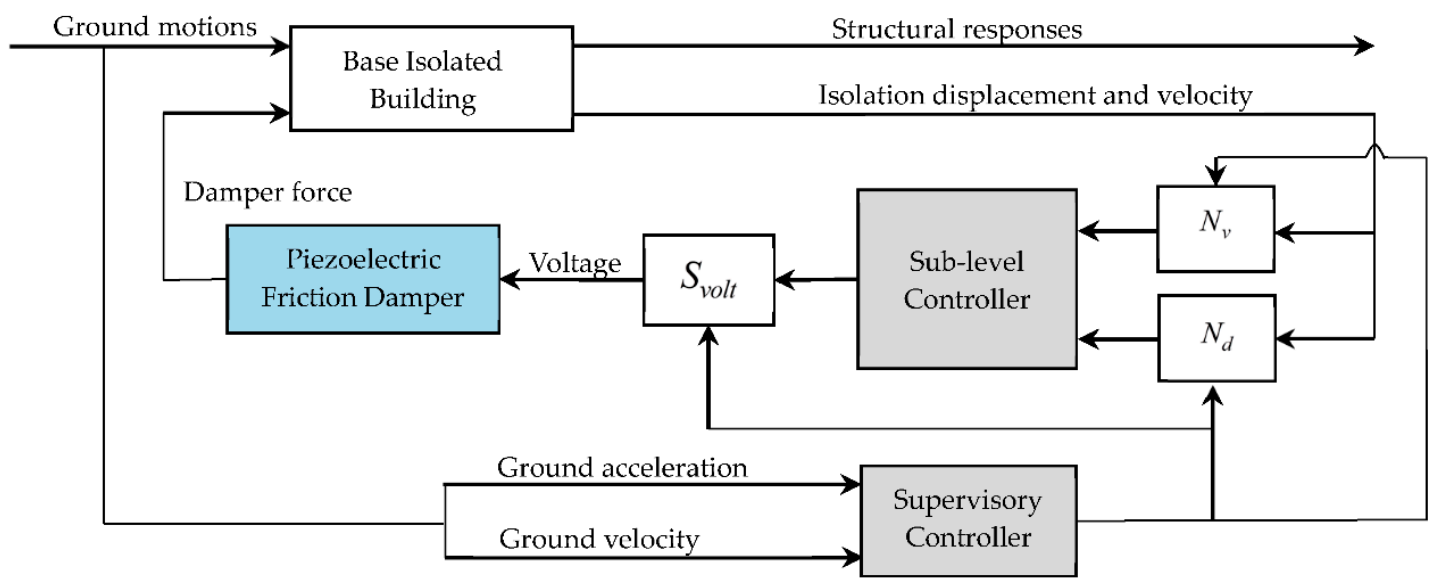

Figure 4. Block diagram of the self-tuning fuzzy control strategy.

\subsection{Self-Tuning Hierarchic Fuzzy Logic Control (SHFLC) Strategy}

Because of the uncertainties and nonlinearities in the nature of the earthquake and the isolation system, as well as the discontinuous characteristics of the friction force of PFD, the development of semi-active control methods is a challenging task. Fuzzy logic approach is an effective method to deal with complex nonlinear systems. It can describe relationships between inputs and outputs of a controller using simple verbose statements instead of complicated mathematical terms. Due to its inherent robustness and simplicity, fuzzy logic theory has been widely used to develop controllers for semi-active devices [17-19].

In the self-tuning hierarchic fuzzy logic control strategy, fuzzy logic controllers (FLC) are used in the design of the sub-level controller and the supervisory controller. In the sub-level FLC, seven Gaussian membership functions were defined for each input variable as shown in Figure 5. The fuzzy sets for the input variables are defined as follows: NL: negative large, NM: negative medium, NS: negative small, ZE: zero, PS: positive small, PM: positive medium, and PL: positive large. Furthermore, the universe of discourse for each input variable ranges from -1 to 1 . Five Gaussian membership functions were defined to cover the universe of discourse of the output variable voltage that varies from 0 to $1000 \mathrm{~V}$. The fuzzy sets for the output variables are defined as: VL: very large, L: large, M: medium, S: small, and ZE: zero.

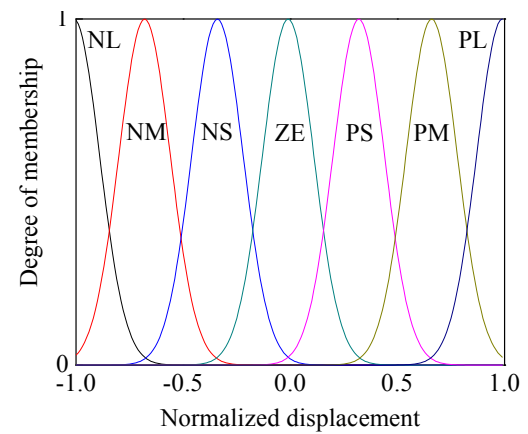

(a)

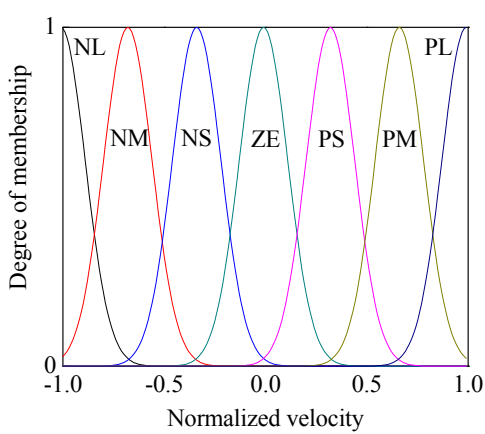

(b)

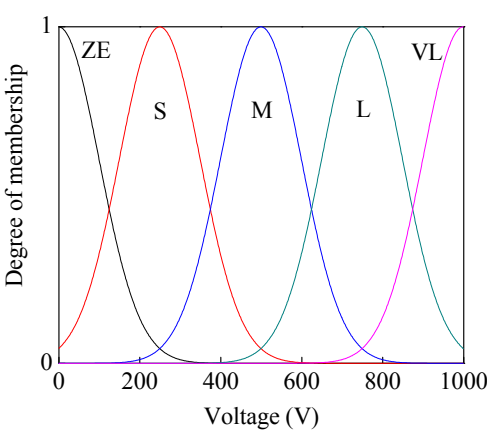

(c)

Figure 5. Input and output membership functions for sub-level fuzzy controller: (a) input normalized displacement; (b) input normalized velocity; and (c) output voltage.

After the fuzzification of the input and output variables, fuzzy control rules were established for the sub-level FLC, as shown in Table 3. The control rules are in the form of if-then rules and map the links between the input and output membership functions. The control principles are as follows: (1) if 
the base displacement and velocity have opposite signs (i.e., the isolation system returns to its original position), then the output voltage becomes small in order to ensure the PFD output small damping force; and (2) if the base displacement and velocity have the same sign, then the output voltage becomes large. At the same time, the magnitude of the output is linearly proportional to the magnitude of the input variables. When the displacement and velocity are almost zero or small, the command voltage is about zero, which means that PFD acts as a passive Coulomb damper. The defuzzification of fuzzy control employs the method of centroid to get a crisp output value. The control surface for the sub-level FLC is shown in Figure 6.

Table 3. Fuzzy rule base for sub-level FLC.

\begin{tabular}{cccccccc}
\hline \multirow{2}{*}{ Isolation Velocity y } & \multicolumn{7}{c}{ Isolation Displacement } \\
\cline { 2 - 8 } & NL & NM & NS & ZE & PS & PM & PL \\
\hline NL & VL & VL & L & L & M & S & ZE \\
NM & VL & L & L & M & S & ZE & S \\
NS & L & L & M & S & ZE & S & M \\
ZE & L & M & S & ZE & S & M & L \\
PS & M & S & ZE & S & M & L & L \\
PM & S & ZE & S & M & L & L & VL \\
PL & ZE & S & M & L & L & VL & VL \\
\hline
\end{tabular}

Note: NL: negative large, NM: negative medium, NS: negative small, ZE: zero, PS: positive small, PM: positive medium, and PL: positive large.

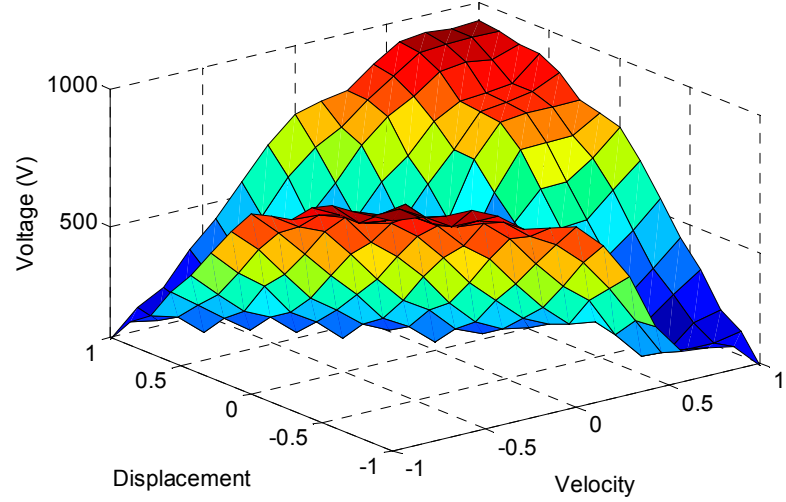

Figure 6. Fuzzy control surface for sub-level FLC.

In order to enhance the adaptability of the proposed control strategy under different types of earthquakes, the type and intensity of earthquakes should be distinguished during the design of the supervisory controller. As discussed above, pulse-type near-fault earthquakes possess large acceleration amplitudes and large long duration velocity impulses. Therefore, seismic acceleration $\ddot{u}_{g}$ and velocity $\dot{u}_{g}$ are selected as the input variables of the supervisory FLC in order to determine the characteristics of the earthquake. The universe of discourse for input seismic velocity is chosen from 0 to $1.8 \mathrm{~m} / \mathrm{s}$. Furthermore, the universe of discourse for input seismic acceleration is chosen from 0 to $4 \mathrm{~m} / \mathrm{s}^{2}$. The outputs of the supervisory FLC are normalization factors $N_{d}$ and $N_{v}$ for the displacement and velocity of the base isolation, and normalization factor $S_{\text {volt }}$ for the voltage of the PFD. It should be noted that normalization factors are used to keep the input variables of the sub-level FLC in the range of the universe of discourse. For each input variable, a reasonable normalization factor should be determined. If the factors are too small, the input value of the sub-level FLC will be converted to a small value in the universe of discourse, and the output voltage will be too low. Thus, the performance of the PFD cannot be fully utilized. On the other hand, if the factors are too large, the input value will be converted to a larger value in the universe of discourse. This will lead to a large 
damping force and limit the effectiveness of the controller. The supervisory FLC can automatically adjust the value of the normalization factors to different types and intensities of earthquakes. To also ensure that the PFD will operate in an effective manner during a non-pulse-type near-fault earthquake or a far-field earthquake, a lower command voltage would be necessary for the damper otherwise, the damping force will be too large. If that were the case, the damper would not dissipate much energy since it would not slide as expected. On the other hand, to ensure that the damping force is not reduced too much, therefore not providing enough energy dissipation under strong earthquakes, such as pulse-type near-fault earthquakes, the output scaling factor with a range from 0 to 1.3 was used to scale the command voltage of the piezoelectric friction damper.

In the preliminary simulations, the universe of discourse for each normalization factor was selected according to the maximum structural response of the base-isolated building subjected to different types and intensity of earthquakes. Gaussian-type membership functions were selected for both input and output variables, as shown in Figure 7. The membership functions of the input variables are defined as S: small, M: medium, and L: large, and the output membership functions are defined as low: LOW, medium: MED and high: HIG.

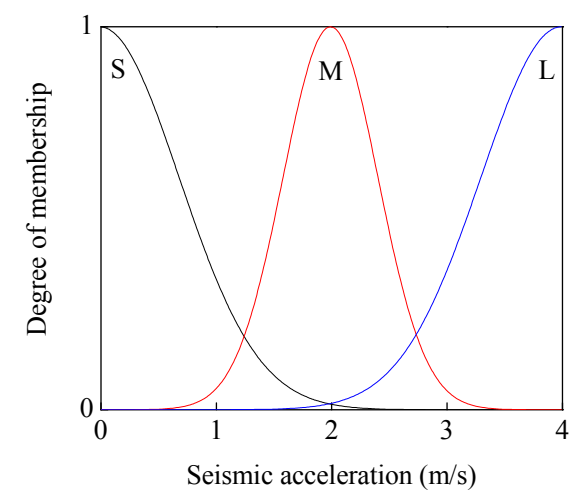

(a)

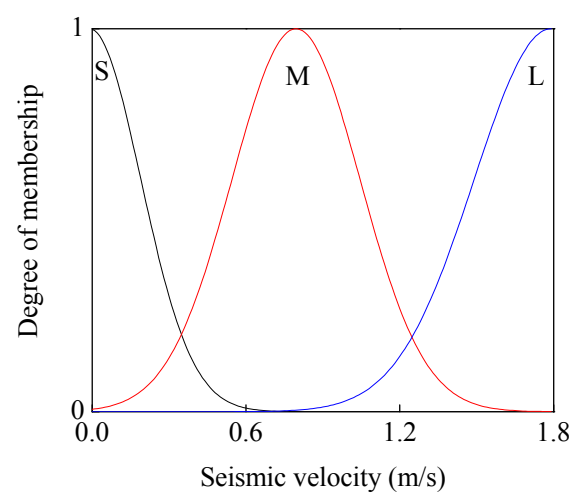

(b)

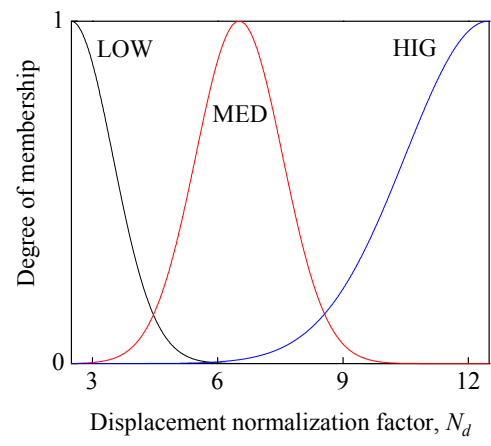

(c)

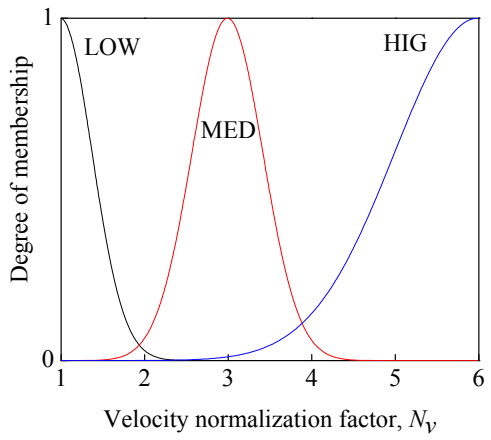

(d)

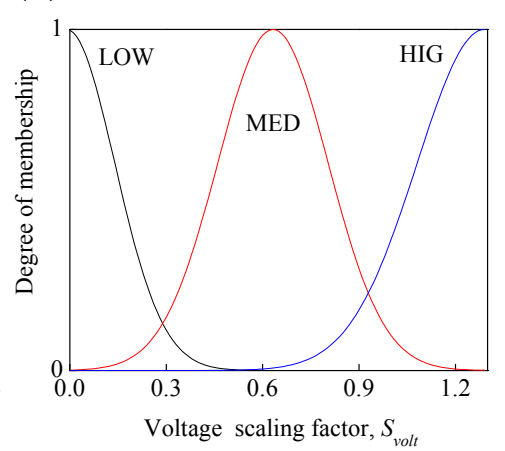

(e)

Figure 7. Input and output membership functions for supervisory FLC: (a) input seismic acceleration; (b) input seismic velocity; (c) output displacement normalization factor; (d) output velocity normalization factor; and (e) output voltage scaling factor.

The control principles for the supervisory FLC are described as follows. If the input values are large (L), which indicate the earthquake intensity is strong and the structural response is large, then the values of normalization factors should be set to low. This will prevent the structural response from over exceeding the input universe of discourse of the sub-level FLC, and avoid the damper to be set in a full power condition for a long time. At the same time, to make the friction damper output a large damping force, the scaling factor $S_{\text {volt }}$ should be increased to enhance the output voltage of the sub-level fuzzy controller. On the contrary, if the input value is small (S) or medium (M), which indicates the earthquake intensity is low and structure response is small, then the normalization factors of the 
sub-level FLC should be appropriately increased. To make the damper output an appropriate damping force, the scaling factor $S_{\text {volt }}$ should be decreased to reduce the output voltage of the sub-level FLC. Furthermore, the smaller damping force can be output by the friction damper. The control rules of the supervisory fuzzy controller are shown in Tables 4 and 5, respectively.

Table 4. Fuzzy rule base for $N_{d}$ and $N_{v}$ of supervisory FLC.

\begin{tabular}{cccc}
\hline \multirow{2}{*}{ Input $\left(\ddot{u}_{g}\right)$} & \multicolumn{3}{c}{ Input $\left(\dot{u}_{g}\right)$} \\
\cline { 2 - 4 } & $\mathbf{S}$ & $\mathbf{M}$ & $\mathbf{L}$ \\
\hline S & HIG & HIG & MED \\
M & HIG & MED & LOW \\
L & MED & LOW & LOW \\
\hline
\end{tabular}

Table 5. Fuzzy rule base for $S_{\text {volt }}$ of supervisory FLC.

\begin{tabular}{cccc}
\hline \multirow{2}{*}{ Input $\left(\ddot{u}_{g}\right)$} & \multicolumn{3}{c}{ Input $\left(\dot{u}_{g}\right)$} \\
\cline { 2 - 4 } & $\mathbf{S}$ & $\mathbf{M}$ & $\mathbf{L}$ \\
\hline S & LOW & LOW & MED \\
M & LOW & MED & HIG \\
L & MED & HIG & HIG \\
\hline
\end{tabular}

\section{Numerical Simulations}

A total of sixteen earthquake records, shown in Table 1, were selected to evaluate the performance of the proposed self-tuning hierarchic fuzzy control strategy. The peak accelerations of the earthquakes are scaled to $0.4 \mathrm{~g}$. A series of time history analyses for the base-isolated structure were performed with MATLAB/Simulink under the mentioned earthquakes. To evaluate the performance of the base-isolated structure for different cases, a total of nine performance indices are employed in this paper, as shown in Table 6 [27]. Here, the performance indices $J_{1}$ through $J_{5}$ denote peak base shear, peak structural shear, peak base displacement, peak inter-story drift, and peak floor acceleration in the controlled structure normalized by the corresponding values in the uncontrolled structure, respectively; $J_{7}$ and $J_{8}$ denote root mean square (RMS) base displacement and floor accelerations of the controlled structure that are normalized likewise, respectively; $J_{6}$ denotes the peak force generated by piezoelectric friction dampers normalized by the peak base shear in the controlled structure; and $J_{9}$ denotes energy dissipated by the dampers normalized by the earthquake input energy to the controlled structure.

Table 6. Performance indices.

\begin{tabular}{ccc}
\hline Peak Base Shear & Peak Inter-Story Drift & RMS Base Displacement \\
\hline$J_{1}=\frac{\max _{t}\left\|V_{0}(t)\right\|}{\max _{t}\left\|\hat{V}_{0}(t)\right\|}$ & $J_{4}=\frac{\max _{t, f}\left\|d_{f}(t)\right\|}{\max _{t, f}\left\|\hat{\hat{d}}_{f}(t)\right\|}$ & $J_{7}=\frac{\max _{i}\left\|\sigma_{d}(t)\right\|}{\max _{i}\left\|\hat{\mathrm{o}}_{d}(t)\right\|}$ \\
\hline Peak Structural Shear & Peak Floor Acceleration & RMS Floor Acceleration \\
\hline$J_{2}=\frac{\max _{t}\left\|V_{1}(t)\right\|}{\max _{t}\left\|\hat{V}_{1}(t)\right\|}$ & $J_{5}=\frac{\max _{t, f}\left\|a_{f}(t)\right\|}{\max _{t, f}\left\|\hat{⿵}_{f}(t)\right\|}$ & $J_{8}=\frac{\max _{f}\left\|\sigma_{a}(t)\right\|}{\max _{f}\left\|\hat{\mathrm{o}}_{a}(t)\right\|}$ \\
\hline Peak Base Displacement & Peak Control Force & Energy Dissipated by PFD \\
\hline$J_{3}=\frac{\max _{t}\left\|x_{b}(t)\right\|}{\max _{t}\left\|\hat{x}_{b}(t)\right\|}$ & $J_{6}=\frac{\max _{t}\left\|f_{d}(t)\right\|}{\max _{t}\left\|\hat{f}_{d}(t)\right\|}$ & $J_{9}=\frac{\int_{0}^{T} f_{d}(t) \dot{x}_{b}(t) d t}{\int_{0}^{T} V_{0}(t) \dot{U}_{g}(t) d t}$ \\
\hline
\end{tabular}

In Table $6, V_{0}(t)$ and $\hat{V}_{0}(t)$ denote the base shear for the controlled and uncontrolled structures, respectively; $V_{1}(t)$ and $\hat{V}_{1}(t)$ denote the structure shear for the controlled and uncontrolled structures, respectively; $x_{b}(t)$ and $\hat{x}_{b}(t)$ denote the base displacement for the controlled and uncontrolled 
structures, respectively; $d_{f}(t)$ and $\hat{d}_{f}(t)$ denote the inter-story drift for the controlled and uncontrolled structures, respectively; $a_{f}(t)$ and $\hat{a}_{f}(t)$ denote the absolute floor acceleration for the controlled and uncontrolled structures, respectively; $f_{d}(t)$ and $\hat{f}_{d}(t)$ denote the force generated by the PFD and the base shear in the controlled structures, respectively; $\sigma_{d}(t)$ and $\hat{\sigma}_{d}(t)$ denote the RMS base displacement for the controlled and uncontrolled structures, respectively; $\sigma_{a}(t)$ and $\hat{\sigma}_{a}(t)$ the RMS absolute floor acceleration for the controlled and uncontrolled structures, respectively; and $U_{g}(t)$ is vector of the ground accelerations.

To evaluate the influence of the pulse effects of the pulse-type near-fault earthquakes (namely, fling-step effect and rupture forward directivity effect) on the base-isolated structure controlled by the SHFLC, the peak inter-story drift, peak floor acceleration and peak base displacement of the SHFLC isolated structure are firstly evaluated. Figure 8 shows the comparison of the average peak inter-story drift and floor acceleration of the SHFLC isolated structure under the four types of earthquake. It can be seen from the figure that, compared to non-pulse-type near-fault earthquakes (type C) and far-field earthquakes(type D), pulse-type near-fault earthquakes (types A and B) can cause much larger inter-story drifts and floor accelerations at the bottom and center of SHFLC isolated structure, and this will decrease gradually with the height of the floors. It is also noted that, for the type $C$ near-fault earthquakes, the peak inter-story drifts and floor accelerations at the top of the isolated superstructure exceed the corresponding values of the pulse-type near-fault earthquakes. For the pulse-type near-fault earthquakes, the earthquakes containing fling-step effect (type A) can induce much larger responses of the SHFLC isolated superstructure excepting at the bottom floor. In addition, far-field earthquakes (type D) have a minimal influence on the inter-story drifts of SHFLC isolated superstructure.

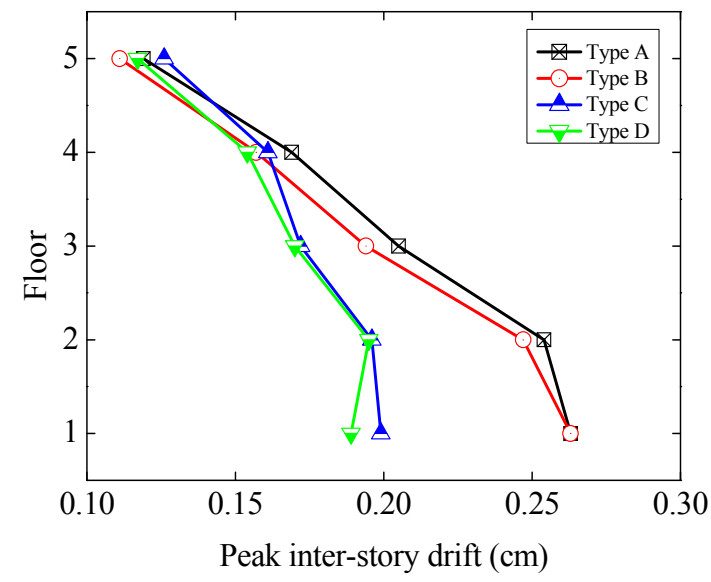

(a)

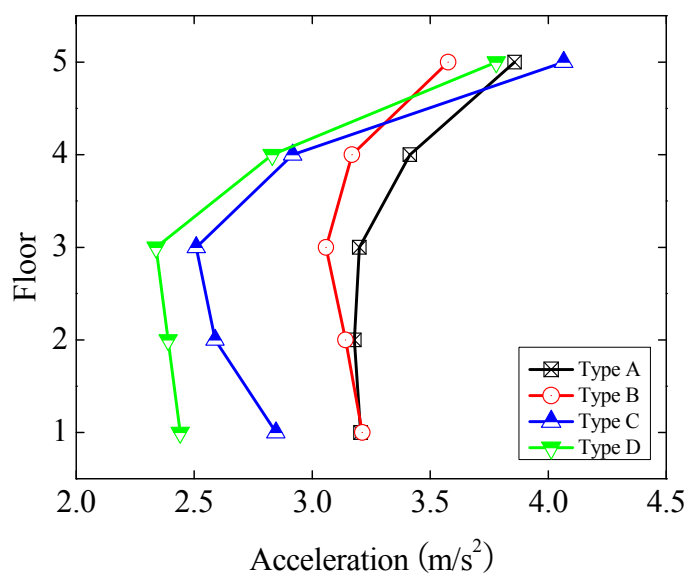

(b)

Figure 8. Average peak inter-story drift and floor acceleration of controlled base-isolated structure subjected to earthquakes: (a) average peak inter-story drift; and (b) average peak floor acceleration.

To explore the influence of pulse-type near-fault earthquakes on base displacements, the peak base displacements of SHFLC isolated structure under four types of earthquakes are shown in Figure 9. It can be seen from this figure that the peak base displacements of SHFLC isolated structure are less than $0.2 \mathrm{~m}$ for most of the pulse-type near-fault earthquakes. For the two types of near-fault earthquakes with the fling-step effect and the rupture forward directivity, the average peak base displacement is $0.167 \mathrm{~m}$ and $0.187 \mathrm{~m}$, respectively. However, the base displacement decreased was evident when subjected to non-pulse-type near-fault and far field earthquakes, with the average peak base displacements equal to $0.065 \mathrm{~m}$ and $0.046 \mathrm{~m}$, respectively. It can be concluded that pulse-type near-fault earthquakes can lead to much larger responses for SHFLC isolated structure as compared to non-pulse-type near fault earthquake and far-field earthquake, especially in the isolation layer and the bottom of the superstructure. 


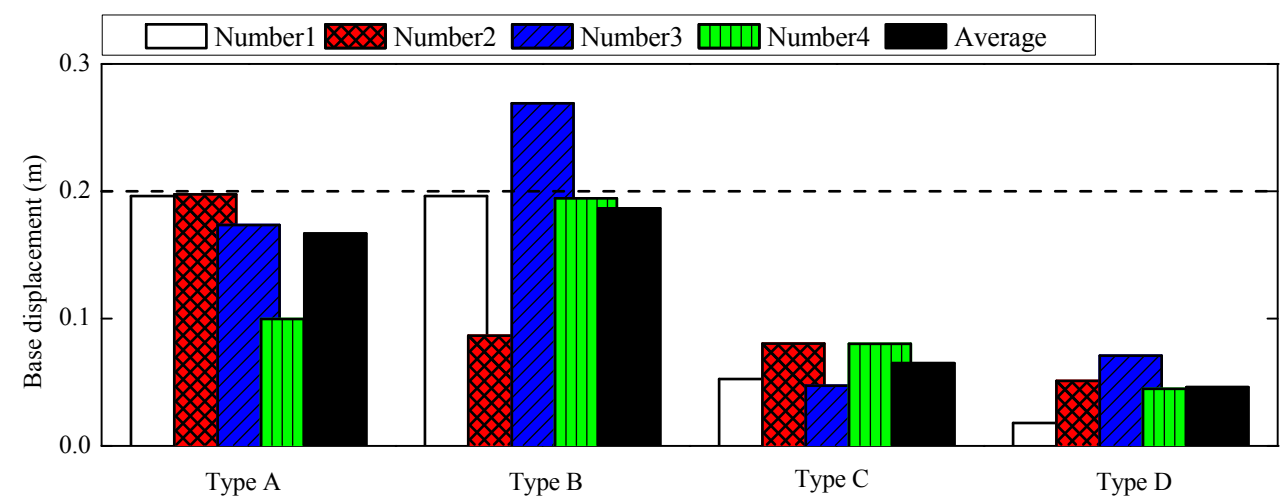

Figure 9. Peak base displacement of controlled base-isolated structure subjected to earthquakes.

The performance indices for the pulse-type near-fault earthquakes and the earthquakes without pulse-effect are listed in Tables 7 and 8, respectively. In these tables, the self-tuning hierarchic fuzzy logic control strategy is named SHFLC. Moreover, for comparison, the results for the maximum passive operation of PFDs are also listed in these tables. Numbers in bold font indicate the best results among the two control cases for the given excitations. Base displacement is an important index to evaluate the effectiveness of the proposed control strategy. For a base-isolated structure subjected to pulse-type near-fault earthquakes, one of the primary purposes is to prevent permanent damage on the isolation bearing or collision with adjacent structures. In these tables, it can be seen that although the maximum passive operation of the PFDs can successfully reduce the performance indices associated with the peak and RMS base displacements $\left(J_{3}\right.$ and $\left.J_{7}\right)$, it will lead to significant amplification in peak and RMS floor acceleration $\left(J_{5}\right.$ and $\left.J_{8}\right)$ for most of the selected earthquakes due to the large constant damper force. For pulse-type near-fault earthquakes, such as A1, A4, B1, B2, and B4, the maximum passive operation of the PFD increases the peak floor acceleration by $40 \%, 74 \%$, $31 \%, 52 \%$ and $33 \%$, respectively, compared to the uncontrolled structure. However, for the earthquake without pulse-effect, the maximum passive operation of the PFD caused an increase in the responses compared to the uncontrolled structure, except for the $\mathrm{C} 4$ earthquake. The increase in peak acceleration $\left(J_{5}\right)$ for $\mathrm{C} 1, \mathrm{C} 2, \mathrm{C} 3, \mathrm{D} 1, \mathrm{D} 2, \mathrm{D} 3$, and D4 are $48 \%, 29 \%, 42 \%, 17 \%, 37 \%, 22 \%$ and $39 \%$, respectively.

Table 7. Performance indices for various control cases under pulse-type near-fault earthquakes.

\begin{tabular}{ccccccccccc}
\hline Earthquake & Control Case & $J_{\mathbf{1}}$ & $J_{\mathbf{2}}$ & $J_{\mathbf{3}}$ & $J_{\mathbf{4}}$ & $J_{\mathbf{5}}$ & $J_{\mathbf{6}}$ & $J_{\mathbf{7}}$ & $J_{\mathbf{8}}$ & $J_{\mathbf{9}}$ \\
\hline \multirow{2}{*}{$\mathrm{A} 1$} & Passive-max & $\mathbf{0 . 8 8}$ & 0.92 & $\mathbf{0 . 6 1}$ & 1.00 & 1.40 & $\mathbf{0 . 6 3}$ & $\mathbf{0 . 7 0}$ & 1.29 & 0.85 \\
& SHFLC & 0.94 & $\mathbf{0 . 9 0}$ & 0.70 & $\mathbf{0 . 9 6}$ & $\mathbf{1 . 2 6}$ & 0.69 & 0.83 & $\mathbf{1 . 1 0}$ & $\mathbf{0 . 7 9}$ \\
\hline \multirow{2}{*}{$\mathrm{A} 2$} & Passive-max & $\mathbf{0 . 9 5}$ & 1.00 & 0.75 & 1.08 & $\mathbf{0 . 8 9}$ & $\mathbf{0 . 6 5}$ & $\mathbf{0 . 8 3}$ & $\mathbf{0 . 7 9}$ & $\mathbf{0 . 8 5}$ \\
& SHFLC & 0.98 & $\mathbf{0 . 9 4}$ & $\mathbf{0 . 7 2}$ & $\mathbf{0 . 9 4}$ & 0.98 & 0.64 & 0.86 & 0.92 & $\mathbf{0 . 8 5}$ \\
\hline \multirow{2}{*}{ A3 } & Passive-max & $\mathbf{0 . 8 3}$ & $\mathbf{0 . 9 3}$ & $\mathbf{0 . 4 1}$ & 1.29 & 0.99 & 0.66 & $\mathbf{0 . 4 6}$ & 0.92 & 0.84 \\
& SHFLC & 0.88 & 0.95 & 0.62 & $\mathbf{0 . 9 5}$ & $\mathbf{0 . 9 3}$ & $\mathbf{0 . 6 6}$ & 0.65 & $\mathbf{0 . 8 1}$ & $\mathbf{0 . 8 9}$ \\
\hline \multirow{2}{*}{ A4 } & Passive-max & $\mathbf{0 . 6 1}$ & $\mathbf{0 . 6 8}$ & $\mathbf{0 . 3 5}$ & 1.14 & 1.74 & 0.57 & $\mathbf{0 . 5 4}$ & 1.46 & 0.76 \\
& SHFLC & 0.79 & 0.76 & 0.47 & $\mathbf{1 . 0 9}$ & $\mathbf{1 . 3 0}$ & $\mathbf{0 . 3 9}$ & 0.66 & $\mathbf{1 . 2 1}$ & $\mathbf{0 . 7 7}$ \\
\hline \multirow{2}{*}{ B1 } & Passive-max & 0.82 & 0.85 & $\mathbf{0 . 6 7}$ & 1.14 & 1.31 & 0.89 & $\mathbf{0 . 7 2}$ & 1.13 & $\mathbf{0 . 8 9}$ \\
& SHFLC & $\mathbf{0 . 7 2}$ & $\mathbf{0 . 7 5}$ & 0.81 & $\mathbf{1 . 0 7}$ & $\mathbf{1 . 1 6}$ & $\mathbf{0 . 8 9}$ & 0.81 & $\mathbf{0 . 9 5}$ & 0.81 \\
\hline \multirow{2}{*}{ B2 } & Passive-max & $\mathbf{0 . 9 4}$ & 0.94 & $\mathbf{0 . 5 4}$ & $\mathbf{0 . 9 5}$ & 1.52 & 0.81 & $\mathbf{0 . 6 3}$ & 1.36 & 0.60 \\
& SHFLC & 0.95 & $\mathbf{0 . 9 5}$ & 0.54 & $\mathbf{0 . 9 5}$ & $\mathbf{1 . 0 2}$ & $\mathbf{0 . 6 8}$ & 0.66 & $\mathbf{0 . 9 1}$ & $\mathbf{0 . 6 4}$ \\
\hline \multirow{2}{*}{ B3 } & Passive-max & 0.98 & 1.01 & 0.63 & $\mathbf{1 . 1 4}$ & 0.97 & $\mathbf{0 . 6 7}$ & $\mathbf{0 . 7 0}$ & 0.81 & $\mathbf{0 . 8 2}$ \\
& SHFLC & $\mathbf{0 . 8 9}$ & $\mathbf{0 . 8 9}$ & $\mathbf{0 . 6 2}$ & $\mathbf{0 . 9 4}$ & $\mathbf{0 . 8 1}$ & 0.78 & 0.83 & $\mathbf{0 . 6 6}$ & 0.78 \\
\hline \multirow{2}{*}{ B4 } & Passive-max & $\mathbf{0 . 9 6}$ & $\mathbf{0 . 9 7}$ & $\mathbf{0 . 5 2}$ & $\mathbf{1 . 0 0}$ & 1.33 & 0.85 & 0.66 & 1.12 & 0.45 \\
& SHFLC & 0.99 & 0.99 & $\mathbf{0 . 5 2}$ & 1.07 & $\mathbf{1 . 2 0}$ & $\mathbf{0 . 5 3}$ & $\mathbf{0 . 6 2}$ & $\mathbf{1 . 0 1}$ & $\mathbf{0 . 5 9}$ \\
\hline
\end{tabular}


Table 8. Performance indices for various control cases under earthquakes without pulse-effect.

\begin{tabular}{ccccccccccc}
\hline Earthquake & Control Case & $J_{\mathbf{1}}$ & $J_{\mathbf{2}}$ & $J_{\mathbf{3}}$ & $J_{\mathbf{4}}$ & $J_{\mathbf{5}}$ & $J_{\mathbf{6}}$ & $J_{\mathbf{7}}$ & $J_{\mathbf{8}}$ & $J_{\mathbf{9}}$ \\
\hline \multirow{2}{*}{ C1 } & Passive-max & 0.92 & 0.92 & 0.66 & 0.94 & 1.48 & 0.43 & 0.74 & 1.34 & $\mathbf{0 . 3 3}$ \\
& SHFLC & $\mathbf{0 . 7 4}$ & $\mathbf{0 . 7 4}$ & $\mathbf{0 . 6 0}$ & $\mathbf{0 . 7 5}$ & $\mathbf{1 . 4 0}$ & $\mathbf{0 . 3 3}$ & $\mathbf{0 . 7 1}$ & $\mathbf{1 . 2 0}$ & 0.28 \\
\hline \multirow{2}{*}{ C2 } & Passive-max & 0.94 & 0.98 & 0.81 & 1.12 & 1.29 & 0.40 & 0.81 & 0.72 & $\mathbf{0 . 4 5}$ \\
& SHFLC & $\mathbf{0 . 9 3}$ & $\mathbf{0 . 9 5}$ & $\mathbf{0 . 7 4}$ & $\mathbf{0 . 9 6}$ & $\mathbf{1 . 0 3}$ & $\mathbf{0 . 4 2}$ & $\mathbf{0 . 7 7}$ & $\mathbf{0 . 5 7}$ & 0.37 \\
\hline \multirow{2}{*}{ C3 } & Passive-max & 0.85 & $\mathbf{0 . 9 3}$ & $\mathbf{0 . 6 2}$ & $\mathbf{0 . 9 3}$ & 1.42 & 0.51 & $\mathbf{0 . 6 7}$ & 1.19 & $\mathbf{0 . 4 1}$ \\
& SHFLC & $\mathbf{0 . 8 1}$ & 0.97 & 0.83 & 0.97 & $\mathbf{1 . 1 7}$ & $\mathbf{0 . 3 3}$ & 0.89 & $\mathbf{0 . 9 7}$ & 0.35 \\
\hline \multirow{2}{*}{ C4 } & Passive-max & $\mathbf{0 . 9 0}$ & $\mathbf{0 . 8 9}$ & $\mathbf{1 . 0 6}$ & $\mathbf{1 . 0 0}$ & $\mathbf{0 . 9 5}$ & 0.45 & $\mathbf{1 . 0 0}$ & 0.85 & $\mathbf{0 . 3 9}$ \\
& SHFLC & 0.98 & $\mathbf{0 . 8 9}$ & 1.21 & 1.09 & 1.07 & $\mathbf{0 . 4 0}$ & 1.15 & $\mathbf{0 . 8 4}$ & 0.32 \\
\hline \multirow{2}{*}{ D1 } & Passive-max & 1.09 & 1.17 & $\mathbf{0 . 6 9}$ & 1.46 & 1.17 & 0.87 & 0.76 & 1.10 & 0.19 \\
& SHFLC & $\mathbf{0 . 8 9}$ & $\mathbf{0 . 9 1}$ & 0.90 & $\mathbf{0 . 9 4}$ & $\mathbf{0 . 8 9}$ & $\mathbf{0 . 5 2}$ & $\mathbf{0 . 8 6}$ & $\mathbf{0 . 7 7}$ & $\mathbf{0 . 2 3}$ \\
\hline \multirow{2}{*}{ D2 } & Passive-max & 1.29 & 1.32 & $\mathbf{0 . 3 9}$ & 1.60 & 1.37 & 0.97 & $\mathbf{0 . 4 2}$ & 1.22 & $\mathbf{0 . 4 1}$ \\
& SHFLC & $\mathbf{0 . 9 6}$ & $\mathbf{0 . 9 9}$ & 0.51 & $\mathbf{1 . 0 0}$ & $\mathbf{1 . 1 4}$ & $\mathbf{0 . 7 2}$ & 0.43 & $\mathbf{1 . 0 3}$ & 0.27 \\
\hline \multirow{2}{*}{ D3 } & Passive-max & $\mathbf{0 . 9 9}$ & 0.93 & $\mathbf{0 . 6 5}$ & $\mathbf{1 . 1 8}$ & 1.22 & 0.70 & $\mathbf{0 . 5 9}$ & 0.96 & $\mathbf{0 . 3 6}$ \\
& SHFLC & 1.03 & $\mathbf{0 . 8 0}$ & 0.75 & 1.27 & $\mathbf{1 . 1 2}$ & $\mathbf{0 . 5 5}$ & 0.69 & $\mathbf{0 . 8 1}$ & 0.27 \\
\hline \multirow{2}{*}{ D4 } & Passive-max & $\mathbf{0 . 7 8}$ & 0.83 & $\mathbf{0 . 5 2}$ & $\mathbf{0 . 8 3}$ & 1.39 & 0.91 & $\mathbf{0 . 5 5}$ & 1.23 & $\mathbf{0 . 4 8}$ \\
& SHFLC & 0.89 & $\mathbf{0 . 6 4}$ & 0.70 & 0.90 & $\mathbf{1 . 3 0}$ & $\mathbf{0 . 5 7}$ & 0.67 & $\mathbf{1 . 1 0}$ & 0.30 \\
\hline
\end{tabular}

Although the SHFLC also increases the peak floor acceleration with respect to the uncontrolled structure under most of the earthquakes, the SHFLC can successfully limit the increase in peak floor accelerations for the selected earthquakes. For example, for A4, B2, C2, and D2 earthquakes, maximum passive operation of PFD increases peak floor acceleration $\left(J_{5}\right)$ by $74 \%, 52 \%, 29 \%$, and $37 \%$, respectively, while SHFLC increases these responses by 30\%, 2\%, 3\%, and $14 \%$. Additionally, the SHFLC case can lead to obvious decreases in RMS floor acceleration $\left(J_{8}\right)$ for most of the selected earthquakes. In addition, it can be seen that the SHFLC case can reduce peak and RMS base displacements for most of the selected earthquakes, which indicates the effectiveness of the proposed control strategy subjected to different types of earthquakes.

According to the definition of performance indices, $J_{3}, J_{5}, J_{7}$ and $J_{8}$ for the uncontrolled base-isolated structure are equal to 1 . In order to graphically compare the control effectiveness of maximum passive control case and the developed SHFLC case with the uncontrolled case for peak and RMS base displacements and floor accelerations, Figures 10 and 11 show the difference between the performance indices $J_{3}, J_{5}, J_{7}$ and $J_{8}$ for control cases and the performance index 1 for uncontrolled case. The vertical coordinate of these figures is the difference between the performance indices and 1 , a negative value indicates that the structural response is reduced relative to the uncontrolled structure, and a positive value illustrates that the structural response is amplified relative to the uncontrolled structure. The absolute value of the vertical coordinate is the proportion of the reduction or amplification. In Figure 10, it can be seen that, compared to the uncontrolled case, the peak and RMS displacements of the base for the two control cases are significantly reduced. The control effect of the maximum passive control for the base displacement is much larger. For the maximum passive control case and the SHFLC case, the average reduction ratios of the peak base displacement under types A and B in Table 1 are $38.3 \%$ and $29.8 \%$, respectively. For the passive control case and SHFLC case, the average reduction ratios of the RMS base displacement are $32.6 \%$ and $25.1 \%$, respectively. However, it can be seen in Figure 11 that the max passive control can significantly amplify the peak and RMS floor acceleration for most of the selected earthquakes. Similarly, for the SHFLC case, the peak and RMS floor accelerations will be amplified for some of the selected earthquakes. For the maximum passive control case and SHFLC case, the average amplification ratios of peak floor acceleration are $27.8 \%$ and $3.7 \%$, respectively. For the maximum passive control case, the average amplification ratio of RMS floor acceleration is $28.3 \%$, while the average reduction ratio of the RMS floor acceleration 
for the SHFLC case is only $9.2 \%$. In summary, as compared to maximum passive control case for all the excitation cases, the SHFLC case produces an average of $24.1 \%$ and $19.1 \%$ reductions in peak and RMS floor acceleration at an expense of an average of $8.5 \%$ and $7.6 \%$ increase in peak and RMS base displacements. In Figures 10 and 11, it can be seen that, compared to the maximum passive control, for most of the excitation cases, the SHFLC case considerably improves the performance of the base-isolated structure in peak and RMS floor accelerations at the cost of slight deterioration of peak and RMS base displacements. Therefore, semi-active operation of PFDs with the SHFLC is more favorable than the passive operation of the dampers in simultaneously suppressing the peak base displacement and peak floor acceleration.

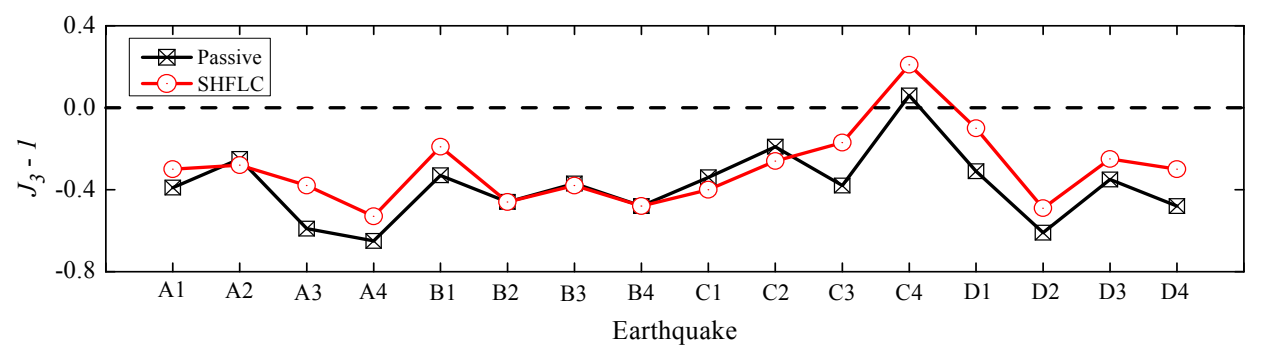

(a)

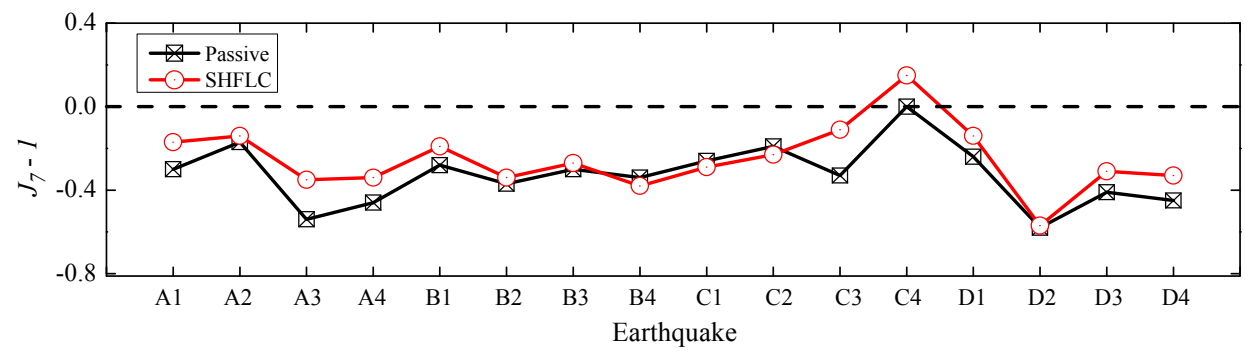

(b)

Figure 10. Performance indices $J_{3}$ and $J_{7}$ for different control cases under various types of earthquakes: (a) Performance index $J_{3}$; and (b) Performance index $J_{7}$.

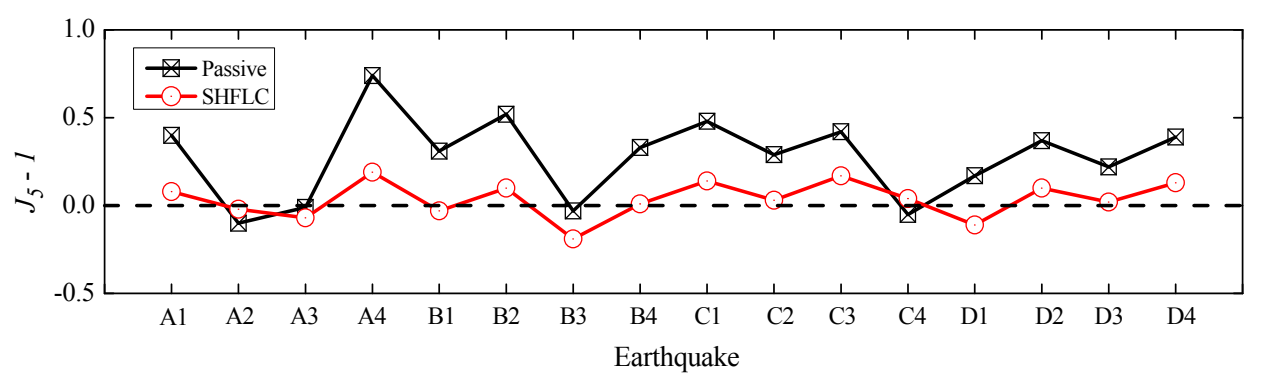

(a)

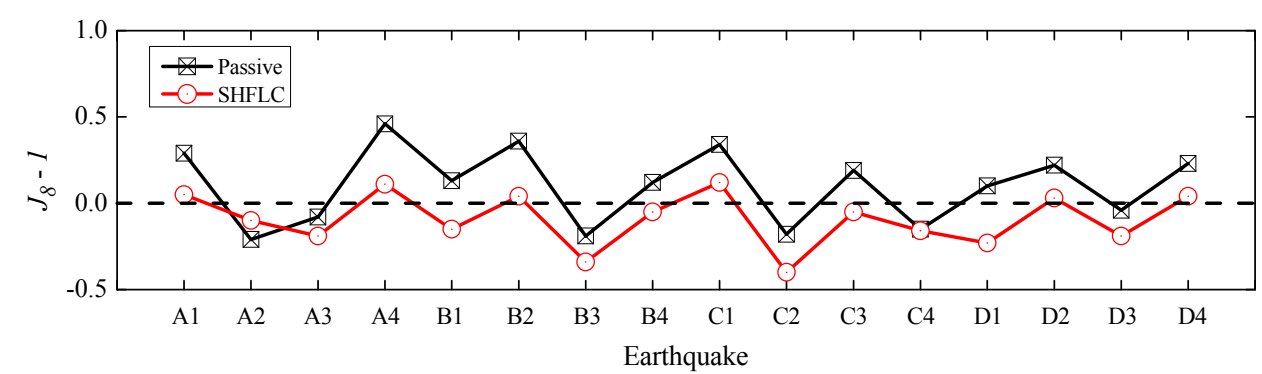

(b)

Figure 11. Performance indices $J_{5}$ and $J_{8}$ for different control cases under various types of earthquakes: (a) Performance index $J_{5}$; and (b) Performance index $J_{8}$. 
Figure 12 illustrates the profiles of average inter-story drifts for uncontrolled, maximum passive control and SHFLC cases. In the figure, it can be seen that the SHFLC case is better than the maximum passive control in inter-story drift reductions of base-isolated structure. Compared with uncontrolled base-isolated structure, there is no obvious amplification in inter-story drifts in the SHFLC case. Furthermore, the inter-story drifts of the SHFLC case at the bottom of the superstructure have an appropriate reduction, which can be illustrated by the performance indices $J_{4}$ shown in Tables 7 and 8, respectively. The values of $J_{4}$ for the SHFLC case subjected to most earthquakes is less than 1, which demonstrates that the peak inter-story drift of the SHFLC case is reduced relative to uncontrolled structure.

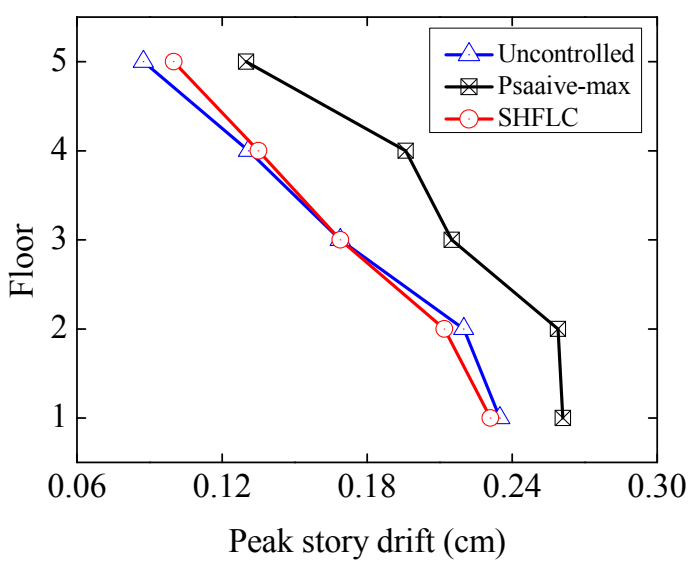

(a)

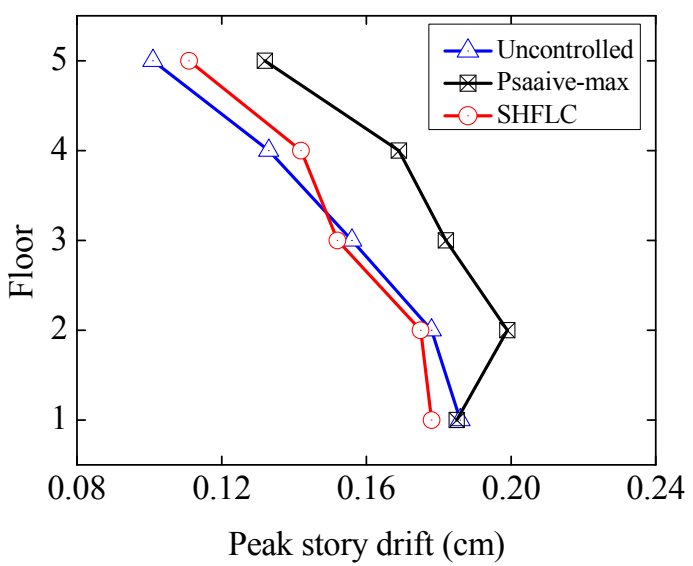

(c)

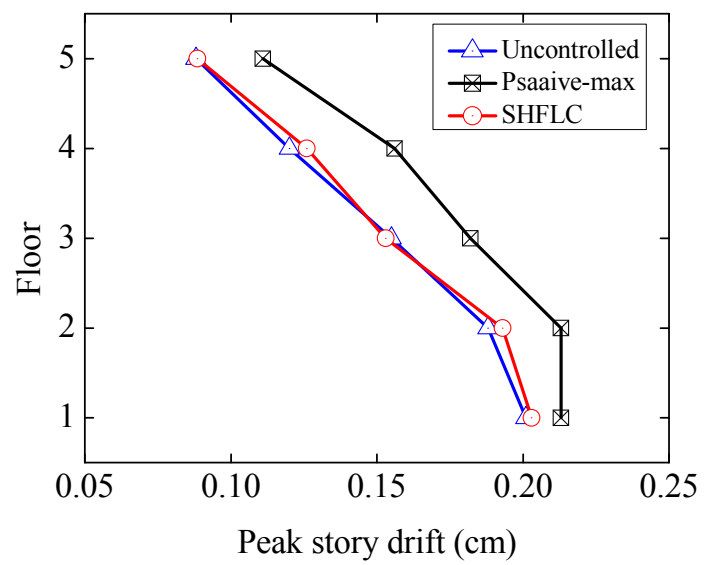

(b)

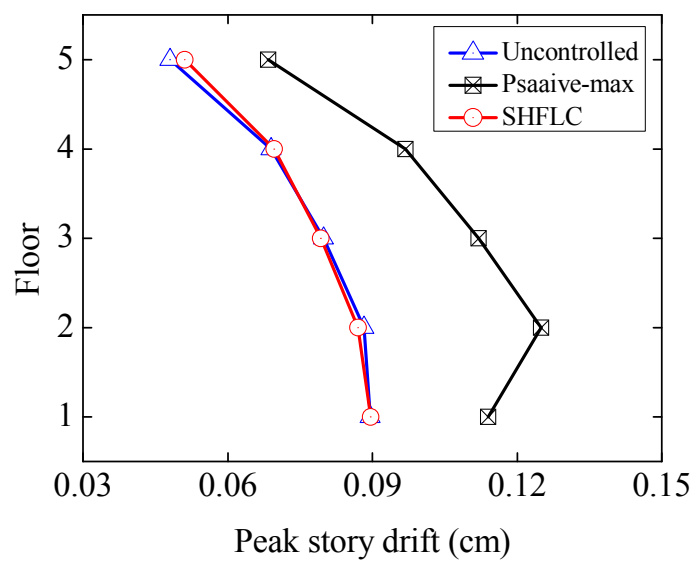

(d)

Figure 12. Average inter-story drifts with four types of earthquakes: (a) near-fault earthquakes with fling effect; (b) near-fault earthquakes with rupture forward directivity; (c) near-fault earthquakes without pulse-effect; and (d) far-field earthquakes.

In order to further evaluate the adaptability of the proposed SHFLC control strategy under different types of earthquakes, the command voltage time history, the damping force time history and the force-displacement curve of the PFD with the SHFLC control strategy are shown in Figure 13, for different earthquake records. As seen in Figure 13, under the pulse-type near-fault earthquakes, such as the TCU068-NS record of the Chi-Chi earthquake with fling effect and the WPI-316 record of the Northridge earthquake with rupture forward directivity, the SHFLC method can output the full amplitude voltage in real time when subjected to large pulse earthquakes. In these cases, large structural responses will be produced and the PFD will output large damping forces to control the base displacement. Therefore, the large output command voltage of the controller will lead to many irregular serrations in the force-displacement curve of the PFD. 

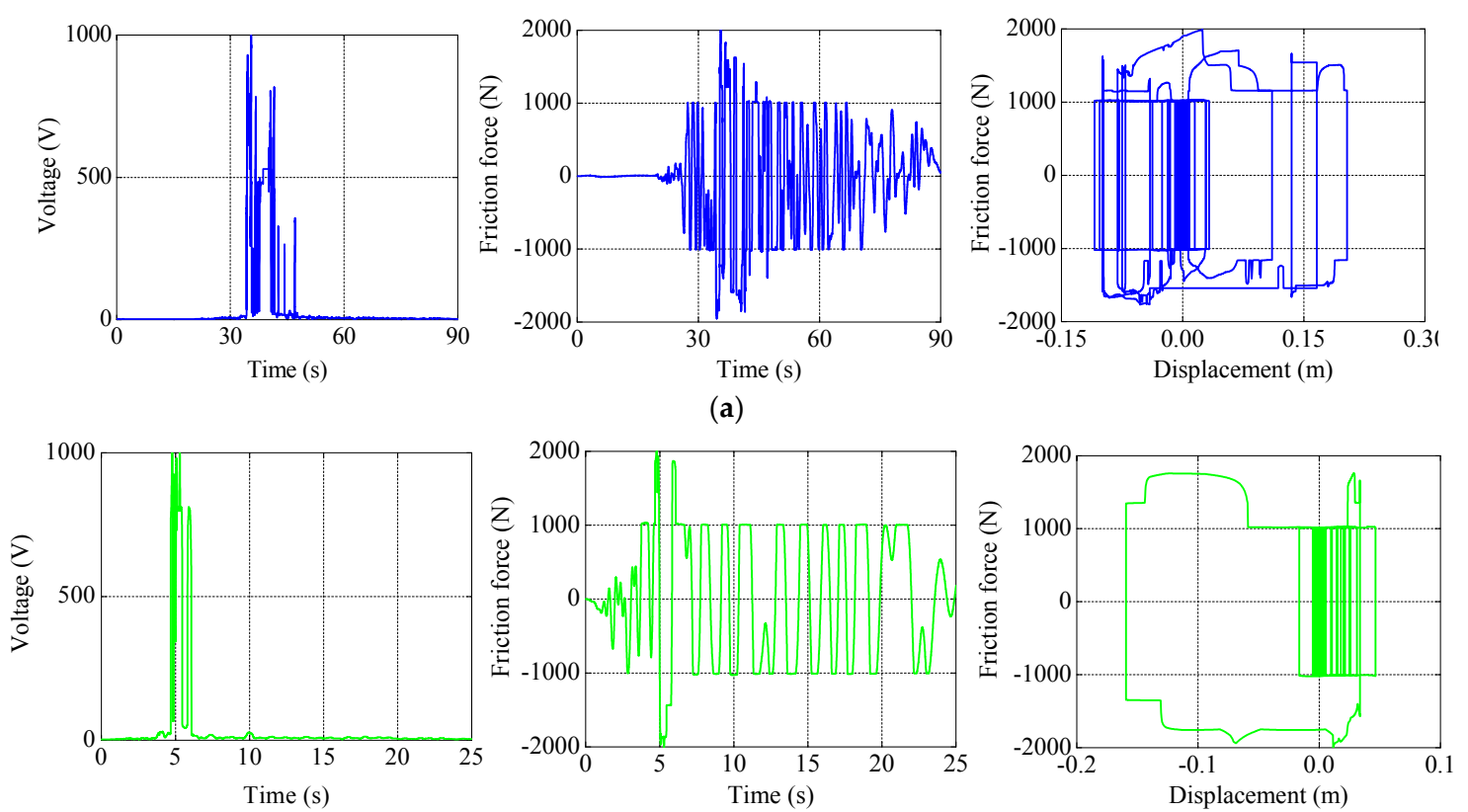

(b)
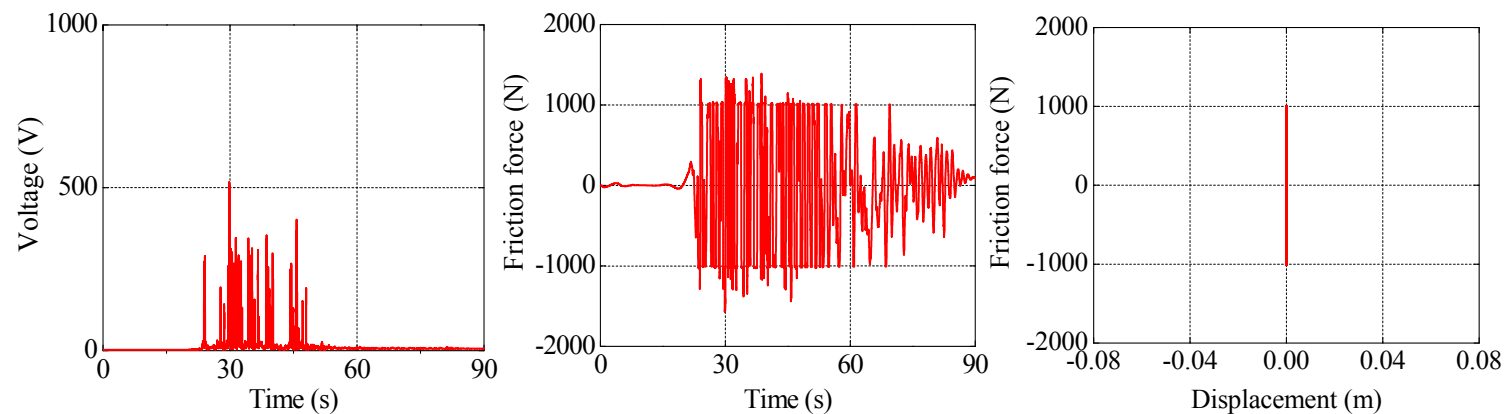

(c)
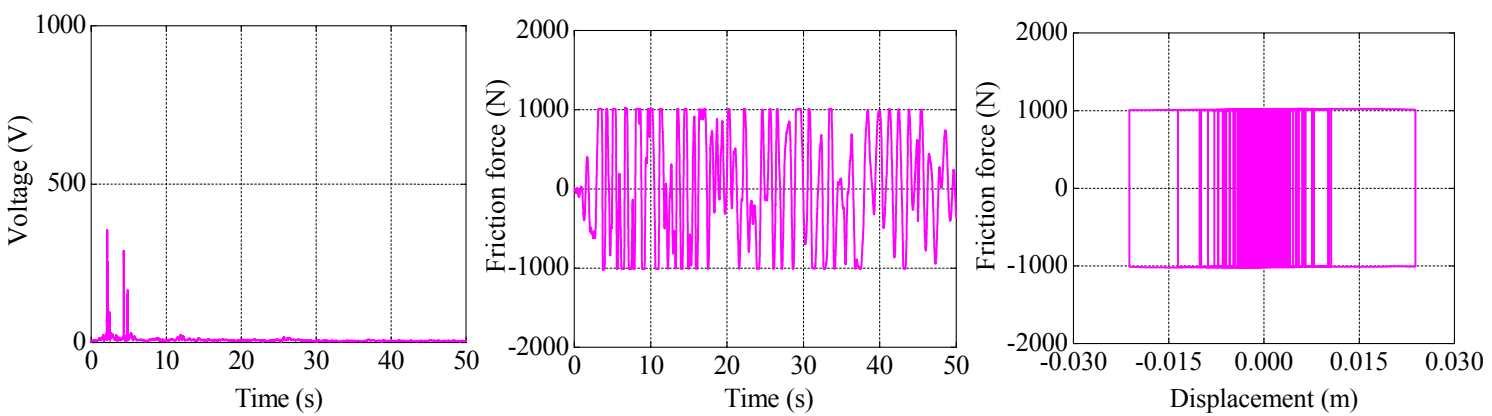

(d)

Figure 13. Time history of command voltage, damper force and force-displacement diagram of PFD under four earthquakes: (a) TCU068-NS record for Chi-Chi earthquake; (b) WPI-316 record for Northridge earthquake; (c) TCU071-EW record for Chi-Chi earthquake; and (d) No.095-S69E record for Taft earthquake.

However, for non-pulse-type near-fault earthquakes and far-field earthquakes, such as the TCU071-EW record of the Chi-Chi earthquake and the No.095-S69E record of the Taft earthquake, the output command voltage of the SHFLC controller is much smaller. In fact, for the No.095-S69E record of the Taft earthquake, the SHFLC controller operates the PFD as a passive Coulomb damper with nearly zero voltage. Therefore, the PFD outputs a small damping force produced by pre-pressure and the force-displacement curve of the PFD is much smoother and similar to that of the passive friction damper. In addition, when comparing the control effort (performance index $J_{6}$ ) of the SHFLC 
controller to that of with the maximum passive controller, it can be seen from Tables 7 and 8 that the SHFLC case requires a much smaller control force to be produced by the PFD for most earthquakes.

In order to further evaluate the performance of the developed control strategy, the energy balance equations of a base-isolated structure are established. For a base-isolated structure with a PFD, the energy equations for the base-isolated structure are expressed as

$$
\begin{gathered}
E_{k}+E_{\xi}+E_{S}+E_{H}=E_{I} \\
E_{k}=\frac{1}{2} \dot{\mathbf{x}}_{\mathbf{t}}^{\mathbf{T}} \mathbf{M} \dot{\mathbf{x}}_{\mathbf{t}} \\
E_{\xi}=\int_{0}^{t} \dot{\mathbf{x}}^{\mathrm{T}} \mathbf{C} d \mathbf{x}=\int_{0}^{t} \dot{\mathbf{x}}^{\mathrm{T}} \mathbf{C} \dot{\mathbf{x}} d t \\
E_{S}=\int_{0}^{t} \mathbf{x}^{\mathrm{T}} \mathbf{K} d \mathbf{x} \\
E_{H}=-\int_{0}^{t} F \mathbf{D}^{\mathrm{T}} d \mathbf{x} \\
E_{I}=-\int_{0}^{t} \ddot{x}_{g} \mathbf{M I} d \mathbf{x}
\end{gathered}
$$

where $E_{k}, E_{\xi}, E_{S}, E_{H}$, and $E_{I}$ denote the absolute kinetic energy, the damping energy, the elastic strain energy, the hysteretic energy provided by the PFD, and the absolute input energy, respectively.

Figure 14 shows the time histories of the input energy $E_{I}$, the viscous damped energy of the structure, lead rubber bearings $E_{\xi}$, and the energy dissipated by the PFD $E_{H}$ for the SHFLC base-isolated building subjected to the $\mathrm{A} 3, \mathrm{~B} 1, \mathrm{C} 1$, and $\mathrm{D} 1$ earthquakes. It can be seen from the figures that the PFD can successfully dissipate most of the input energy of the pulse-type near-fault earthquakes, such as the TCU068-NS record of the Chi-Chi earthquake and the WPI-316 record of the Northridge earthquake. In Table 7, it can be seen that the energy performance indices $J_{9}$ of the base-isolated structure with SHFLC under A3 and B1 earthquakes equal 0.89 and 0.81 , respectively. It can also be seen that the energy performance index $J_{9}$ for the SHFLC case for other pulse-type near-fault earthquakes is generally large. Compared to the maximum passive control case, the energy performance index $J_{9}$ for the SHFLC case can dissipate a lot more energy for most of the pulse-type near fault earthquakes. However, the energy consumption proportion of the PFD controlled with SHFLC will decrease under the earthquakes without pulse effect (types $C$ and D). In Table 8, it can be seen that the energy performance index $J_{9}$ for the SHFLC case is generally less than 0.4. For example, the performance index $J_{9}$ for the SHFLC case subjected to the TCU071-EW record of the Chi-Chi earthquake and the No.095-S69E record of the Taft earthquake are 0.28 and 0.23 , respectively. This means that the energy dissipation proportion of the PFD for the SHFLC case is $28 \%$ and $23 \%$, respectively. From the energy time history curves for the SHFLC case under C1 and D1 earthquakes in Figure 14, it can also be seen that the energy dissipation proportion of the isolation building will increase, which means that most of the seismic input energy will be dissipated. The above results reflect the adaptability of the proposed SHFLC control strategy for different types of earthquakes. 


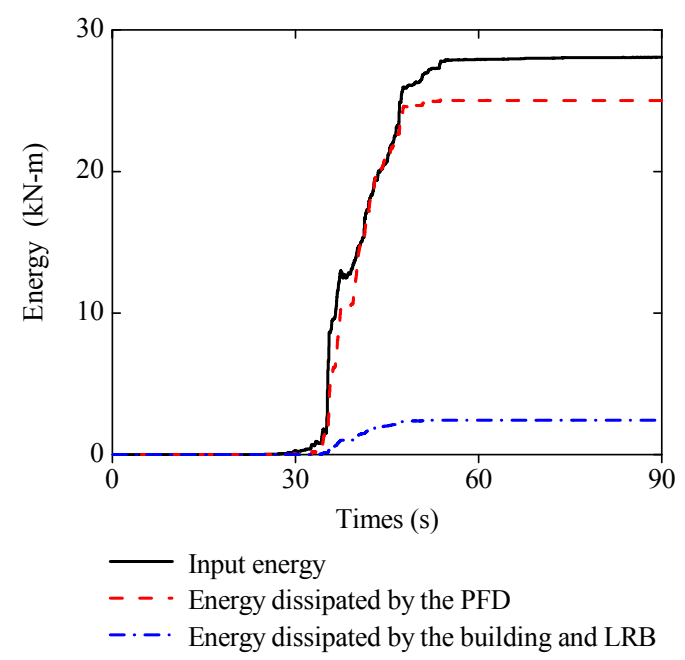

(a)

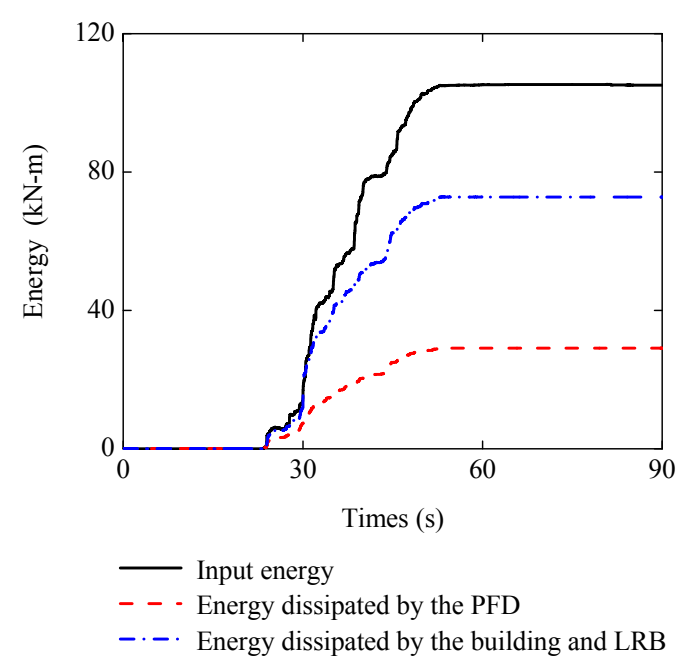

(c)

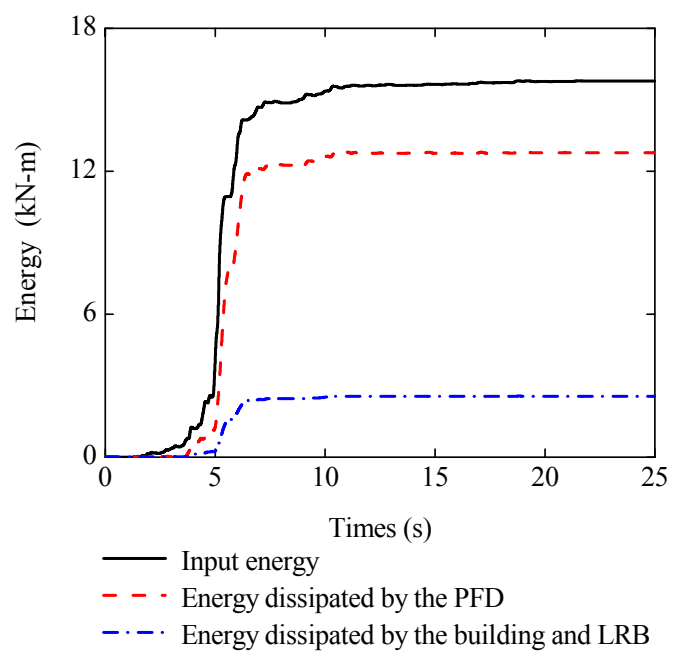

(b)

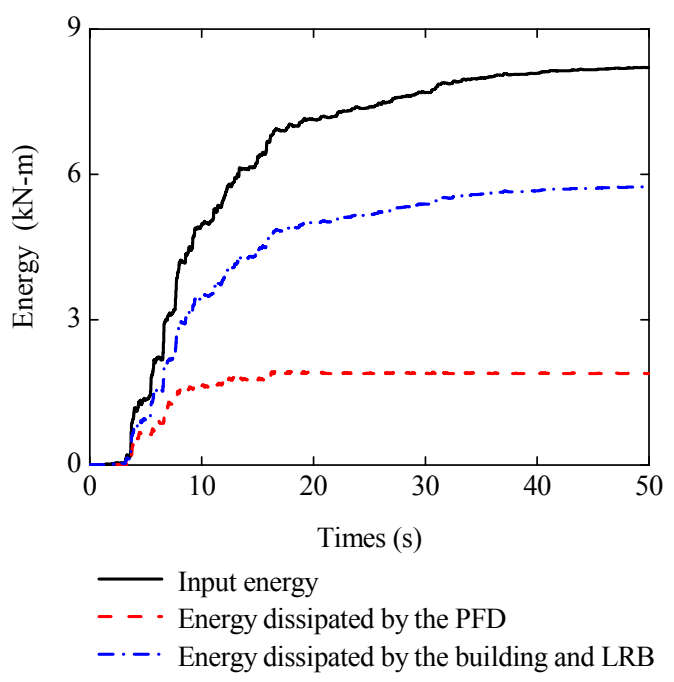

(d)

Figure 14. Energy time histories for a base-isolated structure controlled by SHFLC subjected to four types of earthquakes: (a) TCU068-NS record of Chi-Chi earthquake; (b) WPI-316 record of Northridge earthquake; (c) TCU071-EW record of Chi-Chi earthquake; and (d) No.095-S69E record of Taft earthquake.

\section{Conclusions}

In this study, to simultaneously reduce the responses of isolation system and superstructure for a base-isolated building under various types and intensities of earthquakes, a self-tuning hierarchic fuzzy logic control strategy is proposed and implemented. This controlled method can be mainly divided into two parts. The first part of the developed control strategy, named a supervisory fuzzy logic controller, can adjust two input normalization factors and one output scaling factor of the sub-level fuzzy logic controller in order to identify the type of earthquake. The second controller, namely the sub-level controller in the control strategy, is used to determine the command voltage of the PFD according to the seismic responses of the base-isolated system. Uncontrolled case and maximum passive operation case are compared to the proposed SHFLC strategy to evaluate the performance of the fuzzy controllers. The simulation results reveal that PFDs controlled by the developed strategies can effectively improve the responses of the base-isolated structure against different types of earthquakes including both far-field and near-fault earthquakes. Furthermore, it can be concluded that the proposed SHFLC strategy shows good adaptability to different types of earthquakes. 
Acknowledgments: This research is supported by the National Natural Science Foundation of China (51308487) and Hebei Provincial Natural Science Foundation of China (E2014203055). These supports for this research are greatly appreciated.

Author Contributions: Dahai Zhao conceived the idea, Yang Liu set up the numerical model and analyzed the data, Dahai Zhao and Yang Liu wrote the paper, and Hongnan Li modified the grammar in this paper.

Conflicts of Interest: The authors declare no conflict of interest.

\section{References}

1. Jangid, R.S.; Kelly, J.M. Base isolation for near-fault motions. Earthq. Eng. Struct. Dyn. 2001, 30, $691-707$. [CrossRef]

2. Shen, J.; Tsai, M.H.; Chang, K.C.; Lee, G.C. Performance of a seismically isolated bridge under near-fault earthquake ground motions. J. Struct. Eng. 2004, 130, 861-868. [CrossRef]

3. Mazza, F.; Vulcano, A. Nonlinear response of RC framed buildings with isolation and supplemental damping at the base subjected to near-fault earthquakes. J. Earthq. Eng. 2009, 13, 690-715. [CrossRef]

4. Kalkan, E.; Kunnath, S.K. Effects of fling-step and forward directivity on seismic response of buildings. Earthq. Spectra 2006, 22, 367-390. [CrossRef]

5. Providakis, C.P. Effect of LRB isolators and supplemental viscous dampers on seismic isolated buildings under near-fault excitations. Eng. Struct. 2008, 30, 1187-1198. [CrossRef]

6. Yang, D.; Zhao, Y. Effects of rupture forward directivity and fling-step of near-fault ground motions on seismic performance of base-isolated building structure. Acta Seismol. Sin. 2010, 32, 579-587.

7. Li, S.; Xie, L. Progress and trend on near-field problems in civil engineering. Acta Seismol. Sin. 2007, 29, 102-111. [CrossRef]

8. Ismail, M. Influence of isolation Elimination of torsion and pounding of isolated asymmetric structures under near-fault ground motions. Struct. Control Health Monit. 2015, 22, 1295-1324. [CrossRef]

9. Barbat, A.H.; Rodellar, J.; Ryan, E.P.; Molinares, N. Active control of nonlinear base-isolated buildings. J. Eng. Mech. 1995, 121, 676-685. [CrossRef]

10. Pardo-Varela, J.; de-la-Llera, J.C. A semi-active piezoelectric friction damper. Earthq. Eng. Struct. Dyn. 2015, 44, 333-354. [CrossRef]

11. Ozbulut, O.E.; Hurlebaus, S. Optimal design of superelastic-friction base isolators for seismic protection of highway bridges against near-field earthquakes. Earthq. Eng. Struct. Dyn. 2011, 40, 273-291. [CrossRef]

12. Alhan, C.; Gavin, H. A parametric study of linear and non-linear passively damped seismic isolation systems for buildings. Eng. Struct. 2004, 26, 485-497. [CrossRef]

13. Nagarajaiah, S.; Saharabudhe, S. Seismic response control of smart sliding isolated buildings using variable stiffness systems: Experimental and numerical study. Earthq. Eng. Struct. Dyn. 2006, 35, 177-197. [CrossRef]

14. Shook, D.A.; Roschke, P.N.; Ozbulut, O.E. Superelastic semi-active damping of a base-isolated structure. Struct. Control Health Monit. 2008, 15, 746-768. [CrossRef]

15. Madhekar, S.N.; Jangid, R.S. Variable dampers for earthquake protection of benchmark highway bridges. Smart Mater. Struct. 2009, 18, 1-18. [CrossRef]

16. Bitaraf, M.; Hurlebaus, S. Semi-active adaptive control of seismic excited 20-story nonlinear building. Eng. Struct. 2013, 56, 2107-2118. [CrossRef]

17. Das, D.; Datta, T.K.; Madan, A. Semiactive fuzzy control of the seismic response of building frames with MR dampers. Earthq. Eng. Struct. Dyn. 2012, 41, 99-118. [CrossRef]

18. Kim, H.S.; Roschke, P.N. GA-fuzzy control of smart base isolated benchmark building using supervisory control technique. Adv. Eng. Softw. 2007, 38, 453-465. [CrossRef]

19. Ozbulut, O.E.; Stefan, H. Fuzzy control of piezoelectric friction dampers for seismic protection of smart base isolated buildings. Bull. Earthq. Eng. 2010, 8, 1435-1455. [CrossRef]

20. Ozbulut, O.E.; Bitaraf, M.; Hurlebaus, S. Adaptive control of base-isolated structures against near-field earthquakes using variable friction dampers. Eng. Struct. 2011, 33, 3143-3154. [CrossRef]

21. Zhao, D.; Li, Y. Fuzzy control for seismic protection of semiactive base-isolated structures subjected to near-fault earthquakes. Math. Probl. Eng. 2015, 2015, 675698. [CrossRef]

22. Hu, J.; Xie, L. Review of rupture directivity related concepts in seismology. J. Earthq. Eng. Eng. Vib. 2011, $31,1-8$. 
23. Sehhati, R.; Rodriguez-Marek, A.; ElGawady, M.; Cofer, W.F. Effects of near-fault ground motions and equivalent pulses on multi-story structures. Eng. Struct. 2011, 33, 767-779. [CrossRef]

24. Ng, C.L.; Xu, Y.L. Semi-active control of a building complex with variable friction dampers. Eng. Struct. 2007, 29, 1209-1225. [CrossRef]

25. Ribakov, Y. Base-isolated structures with selective controlled semi-active friction dampers. Struct. Des. Tall Spec. build. 2011, 20, 757-766. [CrossRef]

26. Zhao, D.; Li, H. Shaking table tests and analyses of semi-active fuzzy control for structural seismic reduction with a piezoelectric variable-friction damper. Smart Mater. Struct. 2010, 19, 1-9. [CrossRef]

27. Narasimhan, S.; Nagarajaiah, S.; Johnson, E.A.; Gavin, H.P. Smart base-isolated benchmark building. Part I: Problem definition. Struct. Control Health Monit. 2006, 13, 573-588. [CrossRef]

(C) 2017 by the authors; licensee MDPI, Basel, Switzerland. This article is an open access article distributed under the terms and conditions of the Creative Commons Attribution (CC BY) license (http://creativecommons.org/licenses/by/4.0/). 